\title{
La interpretacion prejudicial del Tribunal de Justicia Andino y sus efectos en el arbitraje ${ }^{1}$
}

\section{Prejudicial interpretation of the Andean Tribunal of Justice and its effects in arbitration}

\author{
DAVID NAMÉN BAQUERO²
}

\section{RESUMEN}

El presente artículo analiza la función asignada a la autoridad de comunicaciones para resolver conflictos entre proveedores de redes y servicios de telecomunicaciones en las normas nacionales, la jurisprudencia constitucional y en el derecho comunitario andino, las diferentes interpretaciones prejudiciales del Tribunal de Justicia de la Comunidad Andina y su impacto en la Administración de Justicia, el estado actual de la cuestión y la competencia de los jueces para definir las controversias distintas de las asignadas a la autoridad regulatoria.

Palabras claves: Conflictos entre proveedores y redes de servicios, Comisión de Regulación de Comunicaciones, Derecho Comunitario Andino,Tribunal de justicia de la comunidad Andina, Interpretación prejudicial, Jurisdicción y competencia.

1 Fecha de recepción: 14 de marzo de 2018. Fecha de aceptación: 27 de junio de 2018. Para citar el artículo: Namén D. "La interpretacion prejudicial del Tribunal de Justicia Andino y sus efectos en el arbitraje". En Revist@ E-Mercatoria, vol. 17, n. ${ }^{\circ}$ 1, enero-junio, 2018. DOI: https://doi.org/10.18601/16923960.v17n1.01

2 Abogado de la Universidad Externado de Colombia. LLM en Derecho Internacional Económico y de los Negocios de Georgetown University. Diplomado en Arbitraje Internacional y Resolución de Conflictos de la misma universidad. Docente Investigador del Departamento de Derecho Comercial de la Universidad Externado de Colombia y profesor de Derecho Civil. 


\begin{abstract}
The following article analyses the function assigned to the Colombian Communications authority - CRC- in solving conflicts between network providers and telecommunications services, under domestic regulation, constitutional jurisprudence, Andean Community law, the different prejudicial interpretations of the Andean Community Tribunal of Justice (ATJ) and its impact on the Administration of Justice, the current state of affairs and the competence of local judges to define disputes other than those assigned to the regulatory authority.
\end{abstract}

Keywords: Disputes between network providers and telecommunications services. Colombian Telecommunications Authority. Andean Community Law. Andean Tribunal of Justice. Prejudicial interpretations. Jurisdiction and Competence.

\title{
INTRODUCCIÓN
}

Precisar los conflictos entre proveedores de redes y servicios de telecomunicaciones que deben resolverse por la Autoridad de Regulación de Comunicaciones, el marco de su competencia y atribuciones, reviste una particular relevancia merced al efecto de las interpretaciones prejudiciales adoptadas $a b$ initio por el Tribunal de Justicia de la Comunidad Andina y a los pronunciamientos del Consejo de Estado.

Reiteradas sentencias de constitucionalidad, obligatorias erga omnes a las autoridades y ciudadanos, han señalado con absoluta claridad la naturaleza administrativa de la autoridad regulatoria, sus competencias administrativas, la finalidad, el objeto, el ámbito, los alcances de la regulación y de la función de resolución de conflictos, también del ordenamiento jurídico comunitario andino, la interpretación prejudicial del Tribunal de Justicia de la Comunidad Andina, la jurisdicción y competencia de los jueces internos, y la eficacia del pacto arbitral en materias que no involucren competencias reservadas al juez permanente ni la regulación.

En armonía, la jurisprudencia del Consejo de Estado al principio diferenció las competencias de la autoridad regulatoria y las de los jueces en la solución de conflictos sobre las comunicaciones.

Para cumplir "órdenes" impartidas por el Tribunal de Justicia de la Comunidad Andina en sentencia del 26 de agosto de 2011, y sus interpretaciones prejudiciales -hoy, rectificadas o "moduladas- que "atribuían" competencia privativa a la Autoridad Nacional de Telecomunicaciones para conocer de todo conflicto presentado durante la ejecución de la interconexión, incluidos los contractuales, el Consejo de Estado en sentencia del 23 de septiembre de 
2015 modificó su entonces inalterada línea jurisprudencial, sin que aún exista claridad al respecto.

La cuestión central fue definida por la jurisprudencia constitucional de antes: la Autoridad de Comunicaciones está facultada para conocer, "en el marco de sus competencias" los conflictos concernientes a la regulación; su competencia no es absoluta, general e indiscriminada, sino dentro del estricto marco funcional de la regulación y de sus competencias administrativas ${ }_{i}$ es de derecho estricto, sujeta al principio de legalidad y al principio esencial de la división de poderes públicos; sus funciones de resolución de conflictos "quedan materialmente comprendidas en las de regulación ${ }^{\prime \prime 3}$ y carece de competencia para resolver conflictos ajenos al ámbito de la regulación y de sus precisas competencias.

\section{EL CONFLICTO Y SU TIPOLOGIA}

La voz conflicto designa una divergencia, diferencia o controversia entre dos o más sujetos enfrentados, con posiciones e intereses contrapuestos $y$, por lo tanto, carente de certeza respecto de una relación o situación jurídica ${ }^{4}$.

Las controversias ostentan contenido disímil. Podrán concernir a cualquier derecho, bien o interés con relevancia jurídica ${ }^{5}$, versar sobre derechos e intereses patrimoniales o extrapatrimoniales, contractuales o extracontractuales, civiles, laborales, mercantiles, administrativos, penales $\mathrm{y}$, comprometer, incluso derechos fundamentales.

El conflicto podrá derivar de la formación, celebración, existencia, validez, eficacia, ineficacia, cumplimiento o incumplimiento de un contrato, su reso-

3 Corte Constitucional. Sentencia C-1120-05 y Sentencia C-186-11.

4 Alcalá Zamora y Castillo, Niceto. Proceso de autocomposición y autodefensa. (Contribución al estudio de los fines del proceso) México: Universidad Nacional Autónoma de México, Instituto de Investigaciones Jurídicas, 2000. p. 12.

5 Carnelutti, Francesco. Como nace el Derecho. Sentis Melendo, Santiago y Ayerra REDín, MARINO (trad), Cuarta reimpresión de la tercera edición. Editorial Temis S.A., Bogotái 2004.p. 9; CARnelutTI, FranceSCO. Instituciones del Proceso Civil, vol. I. Sentis MELENDO, SANTIAGO (trad). Buenos Aires: Ediciones Jurídicas Europa-América, 1973, pp. 27-32: "El conflicto actual de intereses se denomina litis. (...) La litis, por tanto, puede definirse como un conflicto (intersubjetivo) de intereses calificado por una pretensión resistida (discutida). El conflicto de intereses es su elemento material, la pretensión y la resistencia son su elemento formal. [...] Una litis, puesto que es un conflicto intersubjetivo de intereses, tiene necesariamente dos sujetos. Cada uno de ellos toma el nombre de parte". DíEZ-PICAZO, LUIS y PONCE DE LEÓN, Experiencias jurídicas y teoría del Derecho, Barcelona: Editorial Ariel S.A, 1993, pp. 5-22: " (...) Un conflicto de intereses existe siempre que entre dos o más personas se produce una situación de tensión o de incompatibilidad en sus necesidades o en sus aspiraciones respecto de los bienes vitales que pueden satisfacerlas (...) En cambio, la controversia es jurídica cuando, además de existir un conflicto de intereses, existe una protección o una tutela preferente de alguno de dichos intereses o una parcial y recíproca tutela de ambos". 
lución, rescisión, responsabilidad contractual, reparación de los daños causados, la mora y sus efectos, el equilibrio económico prestacional o su ruptura y restablecimiento, abuso del derecho, abuso de la posición dominante contractual, pago de una obligación, ejecución forzada o coactiva de la prestación in natura o subrogada o referir a la responsabilidad "extracontractual" en cualquiera de sus modalidades, a su surgimiento, elementos o presupuestos, indemnización plena del daño, involucrar actos de competencia desleal o del derecho societario, los derechos de los consumidores, la propiedad intelectual o industrial la legalidad de actos administrativos, actos, contratos, hechos, omisiones y operaciones, regidos por el derecho administrativo, y más ampliamente a cualquier asunto regulado por el ordenamiento jurídico.

\section{LA RESOLUCIÓN DE CONTROVERSIAS POR LA AUTORIDAD DE REGULACIÓN Y LOS JUECES}

La regulación, control y vigilancia de los servicios públicos $\left(1^{\circ}, 2^{\circ}, 150\right.$ nums. 22 y 23, 189 nums. 22, 333, 334 y 365 a 370 Constitución Política) $)^{6}$, es forma específica de intervención económica del Estado ${ }^{7}$, en los términos que señale la 1 ley ${ }^{8}$ (C.P., art. 150,23; art. 76, inc. primero; art. 365 inc. segundo; y art. 367) ${ }^{9}$.

Procura un mercado sano en términos de equilibrio, regularidad, libertad, competividad y eficiencia, el acceso y prestación eficiente, prevenir o corregir su conculcación en garantía de los fines estatales (C.P., arts. $1^{\circ}, 334,366$ y 367 ), los derechos fundamentales (arts. $2^{\circ}$ y 86 ) y la democracia participativa (C.P., arts. $1^{\circ}, 13,2^{\circ}, 40,78$ y 369), para lo cual, el legislador expide "las leyes que regirán la prestación de los servicios públicos" (art. 150, num. 23) y el Presidente de la República, señala "con sujeción a la ley, las políticas generales de administración y control de eficiencia de los servicios públicos domiciliarios y ejercer por medio de la Superintendencia de Servicios Públicos Domiciliarios, el control, la inspección y vigilancia de las entidades que los presten"(arts. 150, num. 23, 367, 368 y 370 de la C.P) ${ }^{10}$.

6 La regulación de los servicios públicos está asignada al Estado e integrada de los principios (Título I, arts. $1^{\circ}, 2^{\circ}$ y $5^{\circ}$ ) y derechos constitucionales (Título II, arts. $48,49,56,58,60$, $64,67,76,77$ y 78$)$, la facultad de su configuración legislativa, la potestad reglamentaria del Presidente de la República (art. 150, num. 23 y 189, num. 22, respectivamente), las competencias de las entidades territoriales (arts. 106, 289, 302, 311 y 319), las normas del régimen económico y de la hacienda pública (arts. 333 y 334) y las consagradas en el Título XII, Capítulo $5^{\circ}$ a propósito de "la finalidad social del Estado y de los servicios públicos" (arts. 365 a 370). Constitución Política Colombiana.

7 Corte Constitucional, Sentencia C-272 de 1998:"(...) la competencia de regulación de los servicios públicos es genéricamente estatal, (...) por cuanto la Constitución delimita en materia de servicios públicos domiciliarios, algunas órbitas específicas de actuación de las distintas ramas de poder, las cuales deben ser respetadas".

8 Corte Constitucional, Sentencias C-265 de 2002, C-616 de 2002 y C-791 de 2002.

9 Corte Constitucional, Sentencias C-263 de 1996 y C-389 de 2002.

10 La regulación se integra con los principios (Título $\mathrm{I}$, arts. $1^{\circ}, 2^{\circ}$ y $5^{\circ}$ ) y derechos 
La Constitución Política Colombiana contempla algunos "órganos regulatorios" (arts. 76, 77, 113 y 371) ${ }^{11}$ y autoriza su creación (art. 150, nums. $7^{\circ}$ y 23 ; art. 76, inc. primero $;$ art. 211 , art. 365 inc. segundo $;$ y art. 367$)^{12}$. La Ley 142 de 1994 relativa al "régimen de los servicios públicos domiciliarios", define las Comisiones de Regulación ${ }^{13}$ como: "unidades administrativas especiales" con "independencia administrativa, técnica y patrimonial" (artículo 69), "sin personería jurídica, que cumplen funciones administrativas para desarrollar o ejecutar programas propios de un ministerio o departamento administrativo" (art. 67), conformación plural, competencia estricta, ceñida a los actos de creación (arts. 48 y 67), al principio de legalidad y facultad "para dictar normas administrativas de carácter general o particular, de acuerdo con la Constitución, la ley, el reglamento y las directrices presidenciales, dirigidas a las personas que prestan servicios públicos domiciliarios para lograr su prestación eficiente mediante la regulación de monopolios y la promoción de la competencia"14.

Las Comisiones de Regulación son órganos técnicos especializados de creación legal. Su naturaleza y función es estrictamente administrativa; sus actos, ya de contenido general, abstracto e impersonal, ora particular, personal y concreto ${ }^{15}$ son administrativos por su origen, contenido y finalidad (Ley 489 de 1998, art. 68) ${ }^{16}$,

constitucionales (Título II, arts. 48, 49, 56, 58, 60, 64, 67, 76, 77 y 78), la facultad de su configuración legislativa, la potestad reglamentaria del Presidente de la República (art. 150 , num. 23 y 189 , num. 22 , respectivamente), las competencias de las entidades territoriales (arts. 106, 289, 302, 311 y 319), las normas del régimen económico y de la hacienda pública (arts. 333 y 334) y las consagradas en el Título XII, Capítulo $5^{\circ}$ a propósito de "la finalidad social del Estado y de los servicios públicos" (arts. 365 a 370).

11 "Organos de regulación constitucional" o "autoridades independientes", v.gr. Junta Directiva del Banco de la República y Comisión Nacional de Televisión. Cfr. Sentencia C-827 de 2001.

12 Corte Constitucional, Sentencias C-517 de 1992, C-397 de 1995, C-263 de 1996, C-483 de 1996, C-75 de 1997, C-066 de 1997, C-284 de 1997, 272 de 1998, C-444 de 1998,C636 de 2000, C-1162 de 2000, C-290 de 2002, C-389 de 2002, C-617 de 2002 C-35 de 2003 C-150 de 2003, C-503 de 2003, C-741 de 2003 y C-1114 de 2003.

13 Corte Constitucional, Sentencia C-150 de febrero 25 de 2003, caracteriza a las Comisiones de Regulación, además de su creación legal: "(i) son órganos colegiados; (ii) tienen un carácter técnico y especializado (iii) cuentan con independencia patrimonial $_{i}$ (iv) sus directivos, los comisionados, tienen período fijo $;$ (v) y están sometidos a un régimen de conflicto de intereses, incompatibilidades e inhabilidades". En el mismo sentido, Consejo de Estado, Sala de lo Contencioso Administrativo, Sección Tercera, Sentencias de septiembre 25 de 1997, y de noviembre 10 de 1997; Sección Cuarta, Sentencia 9783 de mayo 5 de 2000.

14 Corte Constitucional, Sentencia C-389 de 2002.

15 Corte Constitucional, Sentencias C-557 de 2001, C-031 de 1995, C-069 de 1995, C-193 de 1998, C-957 de 1999,C-638 de 2000; C-646 de 2000.

16 Corte Constitucional, Sentencia C-1120 de 2005: [...] una forma de intervención estatal en la economía para corregir los errores de un mercado imperfecto y delimitar el ejercicio de la libertad de empresa, así como para preservar la sana y transparente competencia, con el fin de lograr una mejor prestación de aquéllos (se refiere a los servicios públicos), y sin que tal función implique la asunción de competencias legislativas o reglamentarias" 
sujetos al principio de legalidad y al control jurisdiccional administrativo ${ }^{17}$, a la Constitución Política, la ley, el reglamento, el acto de delegación de funciones presidenciales (arts. 211 y 370 Constitución Política, 68 de la Ley 142 de 1994 y 48 Ley 489 de 1998 ${ }^{18}$ y al Código de Procedimiento Administrativo y de lo Contencioso Administrativo ${ }^{19}$, obligatorios y oponibles a terceros a partir de su publicación o notificación ${ }^{20}$, esto es, existen desde su expedición, pero su eficacia, obligatoriedad y oponibilidad está condicionada al agotamiento de los medios idóneos de publicidad previstos en el ordenamiento jurídico ${ }^{21}$, cuya omisión, no afecta su existencia y validez ${ }^{22}$ pero excluye sus efectos jurídicos respecto de terceros ${ }^{23}$, y salvo "norma expresa en contrario, los actos administrativos en firme serán obligatorios mientras no bayan sido anulados por la jurisdicción en lo contencioso administrativo" ${ }^{24}$ (art. 91, CPACA).

En nuestro ordenamiento jurídico, la función y competencia administrativa de las Comisiones de Regulación de Servicios Públicos es precisa, singular, específica o concreta y limitada a la materia prevista en la ley. No pueden "ejercer

17 Corte Constitucional, Sentencia C-426 de mayo 29 de 2002 y Consejo de Estado, Sala Plena, Sentencia de 4 de marzo de 2003. Ref.: Exp. IJ030.

18 Corte Constitucional, Sentencia C-1162 de septiembre 6 de 2001, Expediente D-2863: "(...) las comisiones resultan ser tan sólo órganos especializados de carácter técnico encargados de contemplar en la órbita puramente administrativa, con arreglo a la ley y a los reglamentos y previa delegación del Presidente, las pautas orientadas a intervenir en los servicios públicos para preservar el equilibrio y la razonabilidad en la competencia y de esta forma asegurar la calidad de aquéllos y defender los derechos de los usuarios. (...)la regulación de los servicios públicos domiciliarios, [...] es tan sólo una forma de intervención estatal en la economía para corregir los errores de un mercado imperfecto y delimitar el ejercicio de la libertad de empresa, así como para preservar la sana y transparente competencia, con el fin de lograr una mejor prestación de aquéllos, y sin que tal función implique la asunción de competencias legislativas o reglamentarias". En cuanto al origen de las facultades y atribuciones de las Comisiones, las Sentencias C-066 de 1997 y C-444 de también postulan su asignación directa por el legislador.

19 Corte Constitucional, Sentencia C-558 de mayo 31 de 2001. C-426 de mayo 29 de 2002, y Consejo de Estado, Sala Plena, Sentencia de 4 de marzo de 2003, Ref.: Exp. IJ-030.

20 Cfr. Arts. 209, Constitución Política; 65 y ss, Ley 1437 de 2011 y 119 de la Ley 489 de 1998. El artículo 67 de la Ley 1437 de 2011, dispone: "Las decisiones que pongan término a una actuación administrativa se notificarán personalmente al interesado, a su representante o apoderado, o a la persona debidamente autorizada por el interesado para notificarse".

21 Corte Constitucional, Sentencia C-957 de diciembre 1º de 1999, Ref.: Expediente D-2413.

22 Corte Constitucional, Sentencias C-957 de diciembre $1^{\circ}$ de 1999 , C-640 de agosto 13 de 2002, C-096 de 2001, SU-544 de mayo 24 de 2001, T-419 de 1994, C-161 de 1999. Consejo de Estado, Sala de lo Contencioso Administrativo, Sección Primera, Sentencia julio 7 de 1982; Sección Tercera. Sentencia diciembre 12 de 1983; providencia de 23 de junio de 1994; providencia del 20 de septiembre de 1996, rad. 8335; Sentencia del 30 de enero de 1997, sección primera, rad. 4114.

23 Corte Constitucional, Sentencia C-646, mayo 31 de 2000.

24 Corte Constitucional Sentencias C-069 de febrero 23 de 1995, C-638 de 2000, Expediente D-2666. C-193 de 1998. C-1162 de septiembre 6 de 2001, Expediente D-2863 y C-150 de febrero 25 de 2003. Corte Suprema de Justicia Sentencia 2066 de junio 20 de 1990. 
funciones distintas de las que le atribuyen la Constitución y la ley" (art. 121, Constitución Política), menos aún la función pública jurisdiccional de administrar justicia (arts. 113, 116 y 228 Constitución Política) ${ }^{25}$ y su competencia para resolver conflictos está restringida a sus competencias regulatorias, sin comprender toda clase de controversias. En este contexto, no son jueces, y su función de dirimir conflictos referida estrictamente a la regulación, es general.

En efecto, los artículos $73^{26}$ y 74 de la Ley 142 de 1994 atribuyen a las Comisiones de Regulación de Servicios Públicos, la función de resolver precisos conflictos mediante acto administrativo sujeto a control en vía gubernativa y jurisdiccional.

El artículo 74.3, literal b) de la Ley 142 de 1994, en particular, asignó a la Comisión de Regulación de Telecomunicaciones (CRT), hoy Comisión de Regulación de Comunicaciones (CRC) la función de "[r]esolver los conflictos que se presenten entre operadores en aquellos casos en los que se requiera la intervención de las autoridades para garantizar los principios de libre y leal competencia en el sector y de eficiencia en el servicio", y el artículo 22 [9] de la Ley 1341 de 2009 la de "[r]esolver las controversias, en el marco de sus competencias, que se susciten entre los proveedores de redes $y$ servicios de telecomunicaciones. Ningún acuerdo entre proveedores podrá menoscabar, limitar o afectar la facultad de intervención regulatoria, y de solución de controversias de la Comisión de Regulación de Comunicaciones, así como el principio de la libre competencia" ${ }^{\prime 2}$.

Trátase de función administrativa reglada que ejerce "en el marco de sus competencias", la regulación, y el principio de legalidad, sin ostentar naturaleza jurisdiccional.

Artículo 116 de la Constitución Política modificado por el artículo 1 del Acto Legislativo n. ${ }^{\circ} 3$ de 2002, "Excepcionalmente la ley podrá atribuir función jurisdiccional en materias precisas a determinadas autoridades administrativas. Sin embargo no les será permitido adelantar la instrucción de sumarios ni juzgar delitos".

26 L.142/1994. Artículo 73. Funciones y facultades generales. Las comisiones de regulación tienen la función de regular los monopolios en la prestación de los servicios públicos, cuando la competencia no sea, de hecho, posible; y, en los demás casos, la de promover la competencia entre quienes presten servicios públicos, para que las operaciones de los monopolistas o de los competidores sean económicamente eficientes, no impliquen abuso de la posición dominante, y produzcan servicios de calidad. Para ello tendrán las siguientes funciones y facultades especiales:"(i) Resolver, a petición de cualquiera de las partes, los conflictos que surjan entre empresas, por razón de los contratos o servidumbres que existan entre ellas y que no corresponda decidir a otras autoridades administrativas. La resolución que se adopte estará sujeta al control jurisdiccional de legalidad (Art. 73.8)i,(ii) Resolver, a petición de cualquiera de las partes, los conflictos que surjan entre empresas, y que no corresponda decidir a otras autoridades administrativas, acerca de quién debe servir a usuarios específicos, o en qué regiones deben prestar sus servicios. La resolución que se adopte estará sujeta al control jurisdiccional de legalidad. La resolución debe atender, especialmente, al propósito de minimizar los costos en la provisión del servicio (Art. 73.9).

27 La Ley 1507 de 2012, artículo 20, señala: "La CRC tendrá las siguientes funciones regulatorias en asuntos postales: [...] 9. Resolver las controversias que se susciten entre Operadores de Servicios Postales"(se subraya). 
Así lo señaló la Corte Constitucional en sus sentencias C-1120 de 2005 al declarar exequibles los artículos 73 , numerales 73.8 y 73.9, y 74 , numeral 74.3, b), de la Ley 142 de $1994^{28}$ y C-186 de 2011 que, al acoger el concepto del Procurador General de la Nación, precisó:

28 Corte Constitucional, Sentencia C-1120 de 2005: “(...) Del examen de las funciones de resolución de conflictos entre las empresas de servicios públicos domiciliarios, a cargo de las Comisiones de Regulación, de que tratan las normas demandadas, resulta que: "i) Son funciones de regulación de la prestación de los mencionados servicios, conforme a los criterios expresados en las consideraciones generales de esta sentencia, y, más ampliamente, son funciones de intervención del Estado en las actividades económicas con fundamento en lo dispuesto en el Art. 334 de la Constitución. En efecto, las facultades de resolver tanto los conflictos por razón de los contratos o servidumbres (Num. $73.8 \mathrm{del}$ Art. 73) como los conflictos acerca de quién debe servir a usuarios específicos o en qué regiones deben prestar sus servicios (Num. 73.9 del Art. 73) son desarrollo de la función general prevista en el inciso $1^{\circ}$ del mismo artículo, en virtud del cual a las comisiones de regulación corresponde regular los monopolios en la prestación de los servicios públicos, cuando la competencia no sea, de hecho, posible; y, en los demás casos, la de promover la competencia entre quienes presten servicios públicos, para que las operaciones de los monopolistas o de los competidores sean económicamente eficientes, no impliquen abuso de la posición dominante, y produzcan servicios de calidad.(...) En estas condiciones, tales funciones de resolución de conflictos quedan materialmente comprendidas en las de regulación de la prestación de los servicios públicos domiciliarios a cargo de las comisiones de regulación, con el fin de señalar las políticas generales de administración y control de eficiencia de los mismos, con fundamento en lo dispuesto en el Art. 370 superior y de acuerdo con el contenido de las atribuciones de regulación señalado en repetidas ocasiones por esta corporación. Lo mismo puede afirmarse sobre los conflictos entre operadores en los casos en que se requiera garantizar los principios de libre y leal competencia en el sector y de eficiencia en el servicio, cuya resolución asigna el Art. 74, Num. 74.3, de la Ley 142 de 1994 como función especial a la Comisión Reguladora de Telecomunicaciones. ii) Por otra parte, las decisiones que deben adoptar las Comisiones de Regulación en la solución de los mencionados conflictos tienen carácter de actos administrativos que ponen fin a la actuación administrativa y están sometidas al control de legalidad por parte de la jurisdicción, como expresamente lo señalan los numerales acusados 73.8 y 73.9 del Art. 73 de la Ley 142 de 1994, y aunque en el Art. 74, Num. 74.3, Lit. b), de la misma ley no se hace el mismo señalamiento, debe entenderse así conforme a las reglas generales contenidas en el Código Contencioso Administrativo. De lo anterior se concluye que las funciones de resolución de conflictos de que tratan las normas acusadas son de naturaleza administrativa, no sólo desde el punto de vista formal u orgánico sino también material, y por ende no son de naturaleza judicial. Esta actividad de la Administración Pública o de órganos administrativos corresponde a la denominada función arbitral de los mismos, en cuyo ejercicio actúan como árbitros de los conflictos entre particulares o entre éstos y otro órgano administrativo. Por consiguiente, los apartes normativos impugnados no establecen un trato diferente entre las empresas de servicios públicos domiciliarios y las demás personas, respecto de la administración de justicia, por no ser los conflictos entre las primeras objeto de una decisión judicial, sino de una decisión administrativa reguladora de la prestación de dichos servicios. Ello significa que el trato otorgado por el legislador a dichas empresas en relación con la resolución de los mencionados conflictos es distinto porque su situación es distinta de la de las personas que no prestan esos servicios, por lo cual no es procedente efectuar el examen de igualdad conforme a la jurisprudencia cons- 
"Cabe recordar que en la sentencia C-1120 de 2005 se indicó que la facultad de resolver conflictos debe entenderse como una función de regulación y de intervención en la economía, que supone la expedición de actos administrativos pues no tiene naturaleza jurisdiccional" (subrayas ajenas al texto) ${ }^{29}$

El conflicto podrá presentarse entre la autoridad de regulación, los proveedores de redes y servicios de telecomunicaciones, los usuarios o terceros, unos, algunos o todos, versar sobre la regulación, actos de la autoridad reguladora, la prestación del servicio, la relación jurídica que los vincula, su formación, ejecución o terminación, los derechos, obligaciones y responsabilidad inter partes, daños inferidos a terceros, los derechos y atributos de la personalidad, los derechos constitucionales fundamentales, bienes, contratos, obligaciones, responsabilidad "contractual" o "extracontractual" u otros asuntos, sean de orden público o de libre disposición por las partes.

Por regla general, los derechos son de libre disposición, y por excepción no lo son, bien por su propia naturaleza, ya por expresa prohibición legal.

Las materias propias de la regulación y las competencias reservadas a la autoridad reguladora, no son de libre disposición, pero los derechos particulares patrimoniales de las partes en conflicto, de suyo, suelen serlo, salvo expresa disposición legal contraria ${ }^{30}$, en cuyo caso por mandato constitucional y legal, los únicos autorizados para juzgar los conflictos, son los jueces permanentes, salvo que las partes acuerden el arbitraje, pues la Constitución Política legitima a los sujetos para acudir al arbitraje como "mecanismo alternativo de solución de conflictos mediante el cual las partes defieren a árbitros la solución de una controversia relativa a asuntos de libre disposición o aquellos que la ley autorice" (Art.1, Ley 1563 de 2012)31, a cuyo efecto, requiérese la habilitación de las partes ${ }^{32}$, una controversia actual o potencial sobre un asunto de libre

titucional. En este orden de ideas, tales disposiciones no vulneran tampoco el principio del juez natural, que forma parte integrante del principio del debido proceso judicial, ni el derecho de acceso a la administración de justicia".

29 Cfr. Corte Constitucional, Sentencia C-186 del 16 de marzo de 2011.

30 Corte Constitucional, Sentencia C-098 de 2001: "[... son de libre disposición por su titular, es decir, que frente a ellos exista la libertad de renuncia en un todo o en parte", ${ }^{\prime \prime}$ en sentencias C-242 de 1997 sustrae asuntos relativos al estado civil de las personas; C-294 de 1995, al orden público, buenas costumbres, y derechos de los incapaces; C-330 de 2000, a los derechos mínimos de los trabajadores.

31 Arts. 116 de la Constitución Política, modificado por el Acto Legislativo No. 2 de $2002 ; 8^{\circ}$ "Mecanismos Alternativos" al proceso judicial, modificado por el art. $3^{\circ}$ de la Ley 1285 de 2009), y 13 [3] (modificado por el art. $6^{\circ}$. De la ley 1285 de 2009, del ejercicio de la función jurisdiccional por otras autoridades y por particulares), Ley 270 de 1996 (D.O. 42.745 del 15 de marzo de 1996), "Estatuaria de la Administración de Justicia".

32 Para la Corte Constitucional, Sentencias C-242 de 1997, C-1 140 de 2000, C-060 de 2001, C-035 de 2008 C-211 de 2000, C-330 de 2000, C-878 de 2005, C-1028 de 2012, C-170 
disposición ${ }^{33}$, y salvo norma prohibitiva, algunos asuntos disciplinados en normas de orden público, pueden conocerse por árbitros ${ }^{34}$.

Desde esta perspectiva, la facultad de resolver conflictos por la autoridad reguladora no atañe a"cualquier conflicto"entre proveedores de redes y servicios de telecomunicaciones, ni puede ejercerse en áreas reservadas a la función pública de administrar justicia, atribuida a los jueces permanentes, y en su caso, a los árbitros.

\section{LA JURISDICCIÓN Y COMPETENCIA PRIVATIVA DE LOS JUECES PERMANENTES Ó TRANSITORIOS PARA CONOCER DE CONFLICTOS ENTRE PROVEEDORES DE REDES Y SERVICIOS DE TELECOMUNICACIONES SOBRE ASUNTOS DE LIBRE DISPOSICIÓN DIFERENTES A LA REGULACIÓN}

La función pública de administrar justicia y dirimir conflictos concierne a un valor superior estructural del Estado y a la separación de poderes públicos.

Por mandato constitucional la función jurisdiccional corresponde al juez natural competente, excepcionalmente podrá conferirse en materias precisas a entidades administrativas ${ }^{35} \mathrm{y}$ "[l] os particulares pueden ser investidos transitoriamen-

de 2014, el arbitraje presupone la habilitación "voluntaria", expresa, prístina y precisa de las partes.

33 Corte Constitucional, Sentencia C-098 de 2001: "[...] son de libre disposición por su titular, es decir, que frente a ellos exista la libertad de renuncia en un todo o en parte"; en sentencias C-242 de 1997 sustrae asuntos relativos al estado civil de las personas ${ }_{i}$ C-294 de 1995, al orden público, buenas costumbres, y derechos de los incapaces; C-330 de 2000, a los derechos mínimos de los trabajadores.

34 Por ejemplo, la declaración de nulidad absoluta de un contrato. Corte Constitucional, sentencias C-597 de 1998 y C-248 de 1999; Consejo de Estado, Sala de lo Contencioso Administrativo, Sección Tercera, sentencia del 27 de marzo de 2014, Exp. 26939. Consejo de Estado, Sala de lo Contencioso Administrativo, Tercera, Autos de 4 de abril de 2002, Rad. 20.356 y 14 de agosto de 2003, CP: Rad. 24344: "[ ... ] es posible concluir que el legislador estableció, por una parte, como regla general, que pueden ser objeto de arbitramento los asuntos transigibles $\mathrm{y}$, por otra, como regla especial, que los tribunales de arbitramento pueden pronunciarse sobre la validez y existencia de los contratos, a pesar de no cumplirse, en tal caso, aquella condición". MANTILla EsPINOSA, FABRICIO. "Los límites al consentimiento en el pacto arbitral", en: SILVA ROMERO, EDUARDO (dir.). MANTILLA ESPINOSA, FABRICIO (coord.).El Contrato de Arbitraje. $1^{\mathrm{a}}$ ed. Bogotá: Legis Editores S.A. Colegio Mayor de Nuestra Señora del Rosario-Facultad de Jurisprudencia, 2005, pp. 237 a 254.

35 Dispone el artículo 116 de la Constitución Política modificado por el artículo 1 del Acto Legislativo No. 3 de 2002,:"Excepcionalmente la ley podrá atribuir función jurisdiccional en materias precisas a determinadas autoridades administrativas. Sin embargo no les será permitido adelantar la instrucción de sumarios ni juzgar delitos". La jurisprudencia constitucional ha precisado las reglas exactas bajo las cuales puede atribuirse función jurisdiccional a ciertas autoridades administrativas. Véase: Corte Constitucional, Sentencias C-592 de 1994, C-212 de 1994, C-1143 de 2000, C-1641 de 2000, C-649 de 2001, C-1071 de 2002, C-896 de 2012, C-156 de 2013, C-436 de 2013), cuyo desconocimiento 
te de la función de administrar justicia en la condición de jurados en las causas criminales, conciliadores o en la de árbitros babilitados por las partes para proferir fallos en derecho o en equidad, en los términos que determine la ley" ${ }^{\prime \prime 3}$.

La función arbitral de administrar justicia se confía a "particulares" por "habilitación" de las "partes" en los términos que determine la ley ${ }^{37}$.

La función especial de las Comisiones de Regulación de Servicios Publicos de resolver ciertos conflictos dentro del marco de sus competencias, no es arbitral ni jurisdiccional, sino administrativa y es "ejercida dentro del marco de las competencias que el citado cuerpo normativo encomienda al órgano regulador ${ }^{38}$, y para cumplir su objeto ${ }^{39}$.

A contrariedad, en la normativa nacional, el árbitro por autorización constitucional y habilitación de las partes contenida en el "pacto arbitral", administra justicia, desempeña la función jurisdiccional, está investido de jurisdicción (ius, jus, derecho, y dicere, declarar, "iuris-dictio) y competencia para juzgar las controversias sometidas a su conocimiento (arts. 116 de la Constitución Política, modificado por el Acto Legislativo n. ${ }^{\circ} 2$ de 2002 y 13, Ley 270 de 1996, modificado por el art. $6^{\circ}$ de la Ley 1285 de 2009).

comporta la vulneración simultánea de los artículos 29, 113 y 116, esto es, la separación de las ramas, sus funciones y el debido proceso.

Arts. 116 de la Constitución Política, modificado por el Acto Legislativo n. ${ }^{\circ} 2$ de $2002 ; 80$ ("Mecanismos Alternativos" al proceso judicial, modificado por el art. $3^{\circ}$ de la Ley 1285 de 2009), y 13 [3] (modificado por el art. $6^{\circ}$. De la ley 1285 de 2009, del ejercicio de la función jurisdiccional por otras autoridades y por particulares), Ley 270 de 1996 (D.O. 42.745 del 15 de marzo de 1996), "Estatuaria de la Administración de Justicia".

37 Corte Constitucional, Sentencia 572A de 2014 " [... ] corresponde a la ley determinar (i) los asuntos y la forma en que los particulares pueden administrar justicia como árbitros, (ii) los límites y los términos de dicha habilitación y (iii) las funciones y facultades de los árbitros, que son las mismas de los jueces estatales cuando el arbitraje es en derecho, sin vaciar de contenido el derecho de las personas a llevar sus diferencias ante la justicia arbitral".

38 Corte Constitucional, Sentencia C-186 del 16 de marzo de 2011.

39 Corte Constitucional en Sentencia C-403 de 2010: "5.2.1.1. El artículo 19 de la Ley 1341 de 2009, dispone que la Comisión de Regulación de Comunicaciones es una Unidad Administrativa Especial con independencia administrativa técnica y patrimonial, sin personería jurídica, adscrita al Ministerio de Tecnologías de la Información y las Comunicaciones. Este mismo artículo señala que el objeto de la Comisión es la promoción de la competencia de mercado, evitar el abuso de la posición dominante y regular los mercados de las redes y los servicios de comunicaciones, para que la prestación de los servicios sea económicamente eficiente y refleje altos niveles de calidad. Para cumplir este objeto, el artículo 22 de la Ley 1341 de 2009 enumera 19 funciones a desarrollar por la Comisión, las cuales pueden agruparse según su naturaleza en funciones administrativas y funciones de carácter técnico. Las funciones administrativas están descritas en los numerales 9, 12 a 19 del artículo 22 y de conformidad con ellas, le corresponde a la Comisión: (i) resolver las controversias que se presenten entre los proveedores de redes y servicios de telecomunicaciones". 
Por el pacto arbitral, el tribunal de arbitraje es la autoridad competente para conocer de los conflictos concretos comprendidos en el mismo y en la habilitación ${ }^{40}$.

El acuerdo de arbitraje, concentra en los árbitros la jurisdicción y competencia para juzgar el conflicto concreto ${ }^{41}$.

En su virtud, las partes "renuncian" a hacer valer sus derechos ante el juez permanente y se obligan a acudir a los árbitros ${ }^{42}$.

En cuanto hace a conflictos entre proveedores de redes y servicios de telecomunicaciones, el artículo 22 [9] de la Ley 1341 de 2009 consagró una restricción al pacto arbitral, pues "[n]ingún acuerdo entre proveedores podrá menoscabar, limitar o afectar la facultad de intervención regulatoria, y de solución de controversias de la Comisión de Regulación de Comunicaciones, así como el principio de la libre competencia" ${ }^{43}$, y por lo mismo, sobre asuntos diferentes de libre disposición o autorizados por la ley ${ }^{44}$, genera todos sus efectos, y obliga a las partes a ejercer su derecho fundamental de acceso a la administración de justicia ante los árbitros ${ }^{45}$ para la solución de las controversias, según precisó la Corte Constitucional en Sentencia C-186 de 2011, al declarar exequible el aparte acusado del artículo 22 [9] de la Ley 1341 de 2009.

"Abora bien, aunque no fue demandado es preciso bacer alusión al primer enunciado del numeral 9 del artículo 22 de la Ley 1341 de 2009 para una adecuada comprensión de tal facultad de resolución de conflictos. Este precepto le atribuye a la CRC la función de "resolver las controversias, en el marco de sus competencias, que se susciten entre los proveedores de redes y servicios de telecomunicaciones", se tiene entonces que la facultad de resolución de controversias a la cual bace alusión el precepto demandado es ejercida dentro del marco de las competencias que el citado cuerpo normativo encomienda al órgano regulador, las cuales persiguen fines constitucionalmente legítimos a los que ya se ba becho alusión.

40 Ley 1563 de 2012 , arts. $3^{\circ}, 4^{\circ}, 5^{\circ}, 6^{\circ}, 29,41[1], 69$ y 108. El art. $3^{\circ}$, dispone: "El pacto arbitral es un negocio jurídico por virtud del cual las partes someten o se obligan a someter a arbitraje controversias que hayan surgido o puedan surgir entre ellas. El pacto arbitral implica la renuncia de las partes a hacer valer sus pretensiones ante los jueces. El pacto arbitral puede consistir en un compromiso o en una cláusula compromisoria".

41 Consejo de Estado, Sección Tercera, Sentencia del 11 de marzo de 2004, expediente número 11001-03-26-000-2003-0022-01(25021): 'Y LA SALA ADVIERTE que en el momento en el cual se trabó la relación jurídico procesal en el juicio arbitral todos los conflictos y pretensiones quedaron monopolizados en su decisión al Tribunal de arbitramento, se tornaron en materia de decisión judicial y exclusiva.

42 Corte Suprema de Justicia, Sala de Casación Civil, Sentencia de tutela del 18 de marzo de 2009, Exp. 11001-02-03-000-2009-00393-00.

43 Corte Constitucional, Sentencia C-1120 de 2005.

44 Corte Constitucional Sentencia C-426 del 29 de mayo de 2002.

45 Art. 1, Ley 1563 de 2012: "El arbitraje es un mecanismo alternativo de solución de conflictos mediante el cual las partes defieren a árbitros la solución de una controversia relativa a asuntos de libre disposición o aquellos que la ley autorice" 
De lo anterior se concluye que la restricción de la autonomía de la voluntad privada respecto de acuerdos suscritos entre particulares (proveedores de redes y servicios) para acudir a la justicia arbitral es constitucionalmente legítima porque persigue salvaguardar los poderes de intervención que el Legislador asigna a la CRC, pues de otro modo los particulares podrían obstaculizar el cumplimiento de las competencias y por ende la consecución de los propósitos de intervención que la ley le asigna al órgano regulador, de manera que esta restricción resulta también necesaria para el cumplimiento de las competencias atribuidas a la CRC, y no vacía de contenido la autonomía de la voluntad, porque no se impide que los proveedores de redes y servicios celebren pactos compromisorios respecto de asuntos en las cuales no estén involucradas las competencias de regulación legalmente atribuidas a este organismo" $^{\prime 46}$. (Subrayas ajenas al texto)

En los términos de la sentencia de exequibilidad, los proveedores de redes y servicios de telecomunicaciones pueden celebrar pactos compromisorios en asuntos que no involucren las competencias administrativas de regulación de la Comisión de Regulación de Comunicaciones, ni el principio de la libre competencia.

En consecuencia, la normativa nacional asigna a la Comisión de Regulación de Comunicaciones, la función administrativa de regulación e intervención para lograr específicas finalidades, en cuya obtención tiene la especial de resolver conflictos entre proveedores de redes y servicios de telecomunicaciones dentro del marco de sus competencias y limitada a éstas, sin estar autorizada para decidir otros conflictos, ejercer funciones jurisdiccionales, asumir la jurisdicción y competencia de los jueces permanentes o arbitrales, y por tanto, juzgar conflictos de otra naturaleza, verbi gratia, los derivados de la formación,

Corte Constitucional, Sentencia C-186 del 16 de marzo de 2011. En concepto 5032 del 6 de octubre de 2010, rendido en ese proceso, el Procurador General, indicó: "5. Competencias de la Comisión sobre solución de controversias. El actor parece considerar que todo tipo de conflictos entre proveedores deben ser decididos por la Comisión de Regulación de Comunicaciones, sea cual sea su naturaleza y características. Esta consideración es confusa e injustificada, pues no atiende ni a la naturaleza de las funciones de la Comisión ni a los claros parámetros que fija la Corte en la Sentencia C-1120 de 2005, mediante la cual se precisa el tipo y el alcance de las controversias que pueden resolver las Comisiones de Regulación. En efecto, la Corte considera que las controversias de las que puede ocuparse la Comisión, son aquellas que están referidas a conflictos que tengan origen en asuntos objeto de regulación, los cuales no son transigibles, en la medida en que los particulares no pueden disponer de los intereses involucrados. No sobra recordar que sólo los conflictos en los cuales las partes tienen capacidad dispositiva son susceptibles de arbitramento, como lo anota la Corte en la Sentencia C-098 de 2001. La expresión acusada no impide a los particulares pactar cláusulas compromisorias, como mecanismo para la resolución judicial de sus conflictos, siempre que no se afecten las competencias administrativas de la Comisión. La expresión en comento no vulnera el acceso a la administración de justicia a través el mecanismo arbitral, por cuanto en el mismo no se consagra precepto alguno relacionado con la administración de justicia o con los mecanismos alternativos de solución de conflictos. Por esta razón, tampoco se desconoce el principio de reserva de ley estatutaria, establecida en el literal b del artículo 152 Superior". (Subrayas ajenas al texto). 
celebración, ejecución y terminación de los contratos, o los inherentes a su eficacia o ineficacia, o responsabilidad contractual o extracontractual, como acertadamente la jurisprudencia del Consejo de Estado ${ }^{47}$ y de la Corte Constitucional definieron de vieja data, en relación a los asuntos contractuales ${ }^{48}$, entendió y aplicó el órgano regulatorio ${ }^{49}$.

\section{EL DERECHO COMUNITARIO ANDINO Y LAS INTERPRETACIONES PREJUDICIALES DEL TRIBUNAL DE JUSTICIA DE LA COMUNIDAD ANDINA}

La Constitución Política consagra el deber del Estado de promover la integración económica, social y política con las naciones, particularmente con los paises de América Latina y del Caribe, inclusive para conformar una comunidad latinoamericana de naciones y confiere al congreso la facultad de celebrar tratados internacionales sobre bases de equidad, reciprocidad, igualdad y conveniencia social, en los cuales se transfieran "parcialmente determinadas atribuciones a organismos internacionales que tengan por objeto promover o consolidar la integración económica con otros Estados" (Preámbulo, arts. $8^{\circ}, 9^{\circ} .150-16,189-2,224,226$ y 227) ${ }^{50}$.

47 Consejo de Estado, Sala de lo Contencioso Administrativo, Sección 5a, sentencia del 31 de julio de 2003, Radicación 0144-01(ac): "[... ] conflicto surge en la medida en que Telecom decidió, unilateralmente, adoptar una nueva opción, distinta de la pactada en el contrato, cuyo único efecto se produce Inter partes e implica alterar las condiciones económicas que tuvieron en mente los contratantes al momento de celebrar el contrato. Luego es claro que no se trata de situación alguna que tenga relación con las competencias y funciones de la CRT asignadas en los artículos 73.8 y 74.3. c) de la Ley 142 de 1994, ni de validez y eficacia de la regulación expedida por esta, sino de un asunto estrictamente contractual, para cuya resolución las partes previeron en la cláusula veinte del contrato el mecanismo idóneo"

48 Corte Constitucional, Sentencia C-186 del 16 de marzo de 2011 y Sentencia T-088 de 2004: "La Sala advierte que ETELL contaba y cuenta con serios elementos de juicio para promover esta controversia: Es discutible que una entidad que está llamada a cumplir funciones administrativas, se halle legitimada para avocar el conocimiento de una controversia contractual derivada de la pretensión de una de las partes de variar las cláusulas de un contrato con base en un acto administrativo proferido con posterioridad a la suscripción de aquél. Reflexiónese en esto: Si la regulación de los monopolios y la promoción de la competencia entre las entidades prestadoras de servicios públicos domiciliarios comprendiera la solución de controversias contractuales, susceptibles de alterar las condiciones económicas de los contratos suscritos por aquellas; se impondría concluir que la solución de estas controversias es privativa de la administración y que está excluida de la rama judicial del poder público. No obstante, esto no es cierto pues razones de índole constitucional y legal desvirtúan esa connotación de las funciones de inspección y vigilancia que le asisten a la administración en ese ámbito y reafirman la competencia de la jurisdicción para asumir el conocimiento de controversias contractuales."

49 Comisión de Regulacion de telecomunicaciones y Comisión de Regulación de Comunicaciones- Resoluciones 1345 de 2005; Resolución 1388 de 2005, 1479 de 2006, CRT 1715 de 2007, 1757 de 2007, CRC 4401 de 2014.

50 El Preámbulo acentúa el compromiso de "impulsar la integración de la comunidad latinoamericana"; el artículo 9, que "la política exterior de Colombia se orientará hacia 
Colombia, Bolivia, Chile ${ }^{51}$, Ecuador y Perú, el 26 de mayo de 1969 celebran el "Acuerdo Subregional Andino" ("Pacto Andino", "Acuerdo de Cartagena"), aprobado por ley 8 del 14 de abril de $1973^{52}$, para promover el desarrollo equilibrado y armónico de los Países Miembros mediante la integración y cooperación económica, acelerar su crecimiento, la ocupación, mejorar la calidad de vida y formar un mercado común, originario de la Comunidad Andina de Naciones $(\mathrm{CAN})^{53}$ y del Derecho Comunitario Andino, conformado por las normas del Tratado, sus protocolos y de los órganos comunitarios tendientes a promover o consolidar la integración económica ${ }^{54}$.

la integración latinoamericana y del Caribe"; el numeral 16 del artículo 150 de la Carta, que el Congreso ejerce la función de "[a]probar o improbar los tratados que el gobierno celebre con otros Estados o con entidades de derecho internacional. Por medio de dichos tratados podrá el Estado, sobre bases de equidad, reciprocidad y conveniencia nacional, transferir parcialmente determinadas atribuciones a organismos internacionales que tengan por objeto promover o consolidar la integración económica con otros Estados"; el numeral $2^{\circ}$ del artículo 189, asigna al Presidente como jefe de Estado "[d]irigir las relaciones internacionales (...) y celebrar convenios con otros Estados y entidades de derecho internacional tratados o convenios que se someterán a la aprobación del Congreso"; el artículo 227 que "El Estado promoverá la integración económica, social y política con las demás naciones y especialmente con los países de América Latina y del Caribe mediante la celebración de tratados que sobre bases de equidad, igualdad y reciprocidad, creen organismos supranacionales, inclusive para conformar una comunidad latinoamericana de naciones. La ley podrá establecer elecciones directas para la constitución del parlamento andino y del parlamento latinoamericano".

51 Chile se retiró el 30 de octubre de 1976, y con Decisión 645 de 2006 es Miembro Asociado. Venezuela adhirió el 13 de febrero de 1973, en 2006 denuncia el tratado y en agosto suscribe Memorando de Entendimiento con relación a la aplicación del art. 135 del Acuerdo de Integración Subregional.

52 Modificada por Ley 28 de 1978 [D.O. 34.090 del 29 de mayo de 1974]; Ley 42 de 1978, aprueba el «Protocolo de Lima adicional al Acuerdo de Cartagena", firmado en Lima el 30 de octubre de 1976 y el "Protocolo de Arequipa adicional al acuerdo de Cartagena" firmado en Arequipa el 21 de abril de 1978" [D.O. 35167 de 28 de diciembre de 1978] ; Ley 60 de 1987, aprueba el "Protocolo de Quito", modificatorio del Acuerdo de Cartagena, hecho en la ciudad de Quito el 12 de mayo de 1987 [D.O. 38.171, 31 de diciembre de 187]; Ley 323 de 1996, aprueba el protocolo modificatorio del Acuerdo de Integración Subregional Andino (Acuerdo de Cartagena), suscrito en Trujillo, Perú, el 10 de marzo de 1996 [DO. 42.899, 16 de octubre de 1996], Corte Constitucional Sentencia C-231 de 1997; Ley 458 de 1998, aprueba el "Protocolo modificatorio del Acuerdo de Integración Subregional Andino (Acuerdo de Cartagena de 1997)", hecho en la ciudad de Quito, Ecuador, el 25 de junio de 1997 [D.O. 43.360, 11 de agosto 1998], Corte Constitucional Sentencia C-15 de 1999.

53 Protocolo modificatorio del Acuerdo de Integración Subregional Andino (Acuerdo de Cartagena), suscrito en Trujillo, Perú, el 10 de marzo de 1996.

54 Los artículos 79 y 80 del Pacto Andino, disponen: "Artículo 79.- La Comisión de la Comunidad Andina, a propuesta de la Secretaría General, aprobará un marco general de principios y normas para lograr la liberación del comercio intrasubregional de los servicios. Artículo 80.- El marco general previsto en el artículo anterior se aplicará al comercio de servicios suministrado a través de los siguientes modos de prestación: a) Desde el territorio de un País Miembro al territorio de otro País Miembro; b) En el territorio de un País Miembro a 
El "Protocolo modificatorio del tratado de creación del tribunal de justicia del Acuerdo de Cartagena", suscrito en la ciudad de Cochabamba, Bolivia, a 28 de mayo de 1996, aprobado por Ley 457 de 1998, disciplinó la organización, jurisdicción y competencia del Tribunal de Justicia de la Comunidad Andina, y las acciones ${ }^{55}$.

El Tribunal ${ }^{56}$, tiene jurisdicción en la Comunidad Andina ${ }^{57}$, administra justicia con competencia para conocer de las acciones de nulidad, incumplimiento,

un consumidor de otro País Miembro ${ }_{i}$ c) Por conducto de la presencia comercial de empresas prestadoras de servicios de un País Miembro en el territorio de otro País Miembro; y, d) Por personas naturales de un País Miembro en el territorio de otro País Miembro" El Protocolo modificatorio del Tratado de Creación del Tribunal de Justicia de la Comunidad Andina establece: "Artículo 1. El ordenamiento jurídico de la Comunidad Andina comprende: a) El Acuerdo de Cartagena, sus protocolos e instrumentos adicionales; b) El presente Tratado y sus Protocolos Modificatorios $;$ c) Las decisiones del Consejo Andino de Ministros de Relaciones Exteriores y la Comisión de la Comunidad Andina ${ }_{i}$ d) Las Resoluciones de la Secretaría General de la Comunidad Andina; y e) Los Convenios de integración subregional andina. Artículo 2. Las decisiones obligan a los países miembros desde la fecha en que sean aprobadas por el Consejo Andino de Ministros de Relaciones Exteriores o por la Comisión de la comunidad andina La Decisión 500 del 22 de junio de 2001 adoptada por el Consejo Andino de Ministros de Relaciones Exteriores: "El Estatuto del Tribunal de Justicia de la Comunidad Andina Decisión 500 de 2011), dispone: "Artículo 2.- Naturaleza y características del ordenamiento jurídico de la Comunidad Andina. El ordenamiento jurídico de la Comunidad Andina está conformado por normas fundamentales o de derecho primario y por normas derivadas o de derecho secundario. Las normas de derecho primario están constituidas por los tratados suscritos y ratificados por los Países Miembros en materia de integración comunitaria andina, así como por sus protocolos adicionales y modificatorios. Las normas de derecho secundario o derivado están constituidas por las Decisiones del Consejo de Ministros de Relaciones Exteriores y de la Comisión, por las Resoluciones de la Secretaría General, por los Convenios de Complementación Industrial y otros que adopten los Países Miembros entre sí en el marco del proceso de integración subregional andino. Artículo 3.- Ámbito de aplicación. Las normas del ordenamiento jurídico de la Comunidad Andina se aplican en el territorio de los Países Miembros a todos sus habitantes.."

55 Su artículo 42, dispuso: "Los países miembros no someterán ninguna controversia que surja con motivo de la aplicación de las normas que conforman el ordenamiento jurídico de la Comunidad Andina a ningún tribunal, sistema de arbitraje o procedimiento alguno distinto de los contemplados en el presente Tratado. Los países miembros o los órganos e instituciones del Sistema Andino de Integración, en sus relaciones con terceros países o grupos de países, podrán someterse a lo previsto en el presente Tratado".

56 Son órganos de la Comunidad Andina: el Consejo Presidencial Andino; Consejo Andino de Ministros de Relaciones Exteriores; Comisión de la Comunidad Andina ${ }_{i}$ Secretaría General de la Comunidad Andina Tribunal de Justicia de la Comunidad Andina, Parlamento Andino $_{i}$ Consejo Consultivo Empresarial ${ }_{i}$ Consejo Consultivo Laboral ${ }_{i}$ Corporación Andina de Fomento ${ }_{;}$el Fondo Latinoamericano de Reservas; ${ }_{\text {; }}$ Convenio Simón Rodríguez y los convenios sociales que se suscriban o creen dentro del marco del Sistema Andino de Integración, Universidad Andina Simón Bolívar; y los demás órganos o instituciones que se creen en el futuro.

57 El Acuerdo de Integración Subregional Andina, previó el Tribunal de Justicia de la Comunidad Andina (arts. 40 y 41), y el 28 de mayo de 1979 se suscribe en Cochabamba 
laboral, la interpretación prejudicial, el recurso por omisión o inactividad, y ejerce la función arbitral ${ }^{58}$.

La interpretación prejudicial será solicitada por los jueces nacionales que conozcan de un proceso ${ }^{59}$ en el que deba aplicarse o controvierta alguna de las normas que conforman el ordenamiento jurídico de la Comunidad Andina para asegurar su aplicación uniforme en el territorio de los Estados miembros, se limita a precisar su contenido y alcance sin comprender el derecho nacional ni la calificación de los hechos materia del proceso, y debe adoptarse en la sentencia ${ }^{60}$.

Bolivia, el protocolo modificatorio del Tratado de Creación del Tribunal de Justicia del Acuerdo de Cartagena", aprobado por la Ley 457 del 4 de agosto de 1998 (D.O. 43.360, 11 de agosto de 2008), declarada exequible mediante Sentencia C-227 de 1999.

58 En particular, le corresponde: "declarar la nulidad de las Decisiones del Consejo Andino de Ministros de Relaciones Exteriores, de la Comisión de la Comunidad Andina, de las Resoluciones de la Secretaría General y de los Convenios a que se refiere el literal e) del Artículo 1, dictados o acordados con violación de las normas que conforman el ordenamiento jurídico de la Comunidad Andina, incluso por desviación de poder..." (arts. 17. 22, Protocolo modificatorio; 101-106, Decisión 500 de 2011, Estatuto del Tribunal de Justicia de la Comunidad Andina), decidir el incumplimiento de los países miembros a las "obligaciones emanadas de las normas o Convenios que conforman el ordenamiento jurídico de la Comunidad Andina" (arts. 23 a 31 del Protocolo modificatorio; 107-118, Decisión 500 de 2011, Estatuto del Tribunal de Justicia de la Comunidad Andina.); "... interpretar por vía prejudicial las normas que conforman el ordenamiento jurídico de la Comunidad Andina, con el fin de asegurar su aplicación uniforme en el territorio de los Países Miembros" (art. 32 a 36 del Protocolo modificatorio; 121-128, Decisión 500 de 2011, Estatuto del Tribunal de Justicia de la Comunidad Andina); pronunciarse sobre las solicitudes que se le presenten "cuando el Consejo Andino de Ministros de Relaciones Exteriores, la Comisión de la Comunidad Andina o la Secretaría General, se abstuvieren de cumplir una actividad a la que estuvieren obligados expresamente por el ordenamiento jurídico de la Comunidad Andina" y no haya accedido al requerimiento formulado en tal sentido (art. 37, 129-134, Decisión 500 de 2011, Estatuto del Tribunal de Justicia de la Comunidad Andina $)_{i} "$... dirimir mediante arbitraje las controversias que se susciten por la aplicación o interpretación de contratos, convenios o acuerdos, suscritos entre órganos e instituciones del Sistema Andino de Integración o entre éstos y terceros, cuando las partes así lo acuerden" (art. 38); "conocer las controversias laborales que se susciten en los órganos e instituciones del Sistema Andino de Integración" (arts. 40, 135-139, Decisión 500 de 2011, Estatuto del Tribunal de Justicia de la Comunidad Andina).

59 En la noción de "juez nacional", se incluyen los tribunales arbitrales. En Proceso 03-AI2010, Acción de incumplimiento de la Empresa de Telecomunicaciones de Bogotá S.A. ESP, (ETB S.A. E.S.P.) contra la República de Colombia, Sección Tercera del Consejo de Estado, decisión del 26 de agosto de 2011, el Tribunal de Justicia de la Comunidad Andina, señaló: "Por lo tanto, si los árbitros tienen funciones jurisdiccionales y actúan en última instancia y no dependen de los jueces nacionales; para los efectos de la norma comunitaria actúan como jueces nacionales, es decir, de acuerdo con la interpretación extensiva están incluidos dentro del concepto de juez nacional los árbitros que deciden en derecho, luego, deben solicitar la interpretación prejudicial al Tribunal de Justicia de la Comunidad Andina de manera directa, sin que sea necesaria la participación o mediación de organismos judiciales". En el mismo sentido, providencia del 11 de julio de 2012 (57-IP-2012).

60 Las normas del Tratado, establecen: "Artículo 32. Corresponderá al Tribunal interpretar 
La Decisión 462 de 1999 de la Comisión de la Comunidad Andina, adoptó las "Normas que regulan el proceso de integración y liberalización del comercio de servicios de telecomunicaciones en la Comunidad Andina" ${ }^{11}$, señaló sus objeti$\operatorname{vos}^{62}$, define telecomunicación, servicios de telecomunicaciones e interconexión ${ }^{63}$,

por vía prejudicial las normas que conforman el ordenamiento jurídico del Acuerdo de Cartagena, con el fin de asegurar su aplicación uniforme en el territorio de los Países Miembros. Artículo 33. Los jueces nacionales que conozcan de un proceso en que deba aplicarse algunas de las normas que conforman el ordenamiento jurídico del Acuerdo de Cartagena, podrán solicitar la interpretación del Tribunal acerca de dichas normas, siempre que la sentencia sea susceptible de recurso en derecho interno. Si llegare la oportunidad de dictar sentencia sin que se hubiere recibido la interpretación del Tribunal, el Juez deberá decidir el proceso. Si la sentencia no fuere susceptible de recurso en derecho interno, el Juez suspenderá el procedimiento y solicitará la interpretación del Tribunal, de oficio, en todo caso, o a petición de parte si la considera procedente. Artículo 34. En su interpretación, el Tribunal deberá limitarse a precisar el contenido y alcance de las normas de ordenamiento jurídico del Acuerdo de Cartagena. El Tribunal no podrá interpretar el contenido y alcances del derecho nacional ni calificar los hechos materia del proceso. Artículo 35.- El juez que conozca el proceso deberá adoptar en su sentencia la interpretación del Tribunal. Artículo 36.- Los Países Miembros de la Comunidad Andina velarán por el cumplimiento de las disposiciones del presente Tratado y en particular de la observancia por parte de los jueces nacionales a lo establecido en la presente Sección". En igual sentido, artículos 121 a 128 de la Decisión 500 de 2011, Estatuto del Tribunal de Justicia de la Comunidad Andina, y la Nota informativa sobre el Planteamiento de la Solicitud de Interpretación Prejudicial por los Órganos Judiciales Nacionales del Tribunal de Justicia de la Comunidad Andina.

61 Gaceta Oficial del Acuerdo de Cartagena 01/06/99. Lima 1, de Junio de 1999. La Decisión 439 de 1998 estableció el "Marco General de Principios y Normas para la Liberalización del Comercio de Servicios en la Comunidad Andina", y previó que "en el transcurso de los dos meses siguientes a la entrada en vigencia de esta Decisión, el Comité Andino de Autoridades de Telecomunicaciones (CAATEL), será convocado por la Secretaría General para que, en materia de telecomunicaciones, elabore los Proyectos de Decisión que contengan las normas que regulen el proceso de liberalización del comercio de tales servicios entre los Países Miembros. Dichos Proyectos contemplarán las condiciones para la aplicación de los principios, compromisos y normas contenidos en el presente Marco General"

62 "Artículo.1.- Objetivo La presente Decisión tiene como objetivo fomentar el proceso de liberalización progresiva del comercio de los servicios públicos de telecomunicaciones a fin de alcanzar la creación de un Mercado Común Andino de servicios, contribuyendo así al proceso de integración de la Subregión Andina. Tendrá además los siguientes objetivos específicos: a) Eliminar las restricciones y obstáculos al libre comercio de los servicios públicos de telecomunicaciones, de acuerdo al cronograma establecido en la presente Decisión, b) Propiciar la armonización de las normas necesarias para la conformación del Mercado Común Andino de telecomunicaciones; c) Proponer definiciones comunes de los servicios de telecomunicaciones en los Países Miembros".

63 "Artículo 2. Definiciones. [...] Telecomunicaciones. Toda transmisión, emisión o recepción de signos, señales, escritos, imágenes, sonidos, datos o información de cualquier naturaleza por líneas físicas, medios radioeléctricos, medios ópticos u otros medios electromagnéticos. Servicios de telecomunicaciones. Conjunto de funciones, ofrecidas por un proveedor, que se soportan en redes de telecomunicaciones con el fin de satisfacer necesidades de los usuarios." Interconexión. Todo enlace con los proveedores que suministran redes o 
ámbito de aplicación ${ }^{64}$, la "Protección de la libre competencia" (arts. 28 y 29), los principios de la interconexión (arts. 30 a 33), y dispone en el artículo 32:

"Artículo 32.- Condiciones entre proveedores. Si un proveedor que solicita una interconexión considera que es objeto de actuaciones que violan las normas o los principios de interconexión o de la libre competencia, recurrirá ante las Autoridades Nacionales respectivas de la materia que se trate, las cuales resolverán de acuerdo con su normativa nacional."

En los términos de la Decisión 469 de 1999, las controversias entre países miembros por la aplicación de las normas del ordenamiento jurídico andino serán resueltas según las normas del Tratado del Tribunal de Justicia de la Comunidad Andina, a través de las acciones y el procedimiento previsto en el mismo y en caso de violación de las normas o principios de interconexión o la libre competencia, el proveedor afectado "recurrirá ante las Autoridades Nacionales respectivas de la materia que se trate, las cuales resolverán de acuerdo con su normativa nacional". Refiere, por lo tanto, a las "Autoridades Nacionales" competentes según la materia y normativa nacional.

La Resolución 432 de 2000, Secretaria General de la Comunidad Andina expedida de conformidad con la Decisión 462 de 1999 (Capítulo XIII, Disposiciones Transitorias), a la que debe sujetarse, regula las reglas y principios de la interconexión, regida "por las normas comunitarias andinas y, en lo no previsto, por las disposiciones contenidas en la legislación de cada País Miembro donde se lleve a cabo la interconexión" (art. 35), señala las cláusulas mínimas de los acuerdos de interconexión y ofertas básicas (art. 17), cargos de interconexión, su composición, finalidades, condiciones de eficiencia, sostenibilidad y calidad (arts. 18, 19 y 20), y disponía en su artículo 32:

servicios públicos de transporte de telecomunicaciones con objeto que los usuarios de un proveedor puedan comunicarse con los usuarios de otro proveedor y tener acceso a los servicios suministrados por otro proveedor respecto de los que se contraigan compromisos específicos."

64 Artículo 4. Ámbito de aplicación. La presente decisión se aplica a: a) Todas las medidas de los países Miembros que afecten el acceso a las redes y servicios públicos de transporte de tele- comunicaciones y a la utilización de los mismos por personas de los países Miembros; b) Las medidas adoptadas o mantenidas por un país Miembro que afecten la prestación y el comercio de servicios de telecomunicaciones; c) Las medidas relativas a normalización, respecto de la conexión de equipos a las redes públicas de transporte de telecomunicaciones. Ninguna disposición de esta decisión se interpretará en el sentido de: a) Obligar a un país Miembro a autorizar a un proveedor de servicios de otro país Miembro a establecer, instalar, adquirir, arrendar, explotar o suministrar redes o servicios de telecomunicaciones distintos de los especificados en el artículo 3 de esta decisión; b) Obligar a un país Miembro o que éste a su vez exija a un proveedor bajo su jurisdicción que establezca, instale, adquiera, arriende, opere o suministre redes o ser- vicios de transporte de telecomunicaciones que no se ofrezcan al público en general, Limitar o restringir la libre competencia, establecida en cada uno de los Países Miembros; d) Otorgar menores beneficios a los que haya concedido la normativa nacional de cada País Miembro. 
"Artículo. 32. Sin perjuicio de las acciones previstas en el ordenamiento jurídico andino, cualquier controversia que surja durante la ejecución de la interconexión se tratará de resolver entre las partes. En el caso que éstas no logren un entendimiento que ponga fin a la controversia, la misma deberá ser sometida a consideración de la Autoridad de Telecomunicaciones competente del país donde se realiza la interconexión, por cualquiera de las partes. La Autoridad de Telecomunicaciones competente deberá decidir dentro de un plazo máximo de cuarenta y cinco (45) días calendario contados a partir de la recepción de la consulta"65. (subrayas fuera de texto)

Sin perjuicio de las acciones previstas en el ordenamiento jurídico andino (arts. 23 a 31 del Tratado de Creación del Tribunal de Justicia de la Comunidad Andina, y 49, 107 a 111 de su Estatuto), "cualquier controversia que surja durante la ejecución de la interconexión" no resuelta por las partes, se someterá a "consideración" de la Autoridad de Telecomunicaciones competente del país donde se realiza la interconexión, para que decida lo pertinente. La norma consagraba el deber de someter a consideración "de la Autoridad de Telecomunicaciones competente del país donde se realiza la interconexión" la controversia presentada durante la ejecución de la interconexión, para que en el marco de sus competencias decida lo pertinente dentro de un plazo máximo de 45 calendario "contados desde la recepción de la consulta". ¿Qué dispone en rigor?: ¿una consulta? o cla competencia privativa para decidir la controversia?

En armonía con el artículo 32 de la Decisión 469 de 1999, norma de mayor jerarquía, la competencia de las autoridades nacionales se determina por la normativa nacional según la materia de que se trate. Entendida en cuanto en el sentido de asignar competencia a la Autoridad de Telecomunicaciones, la norma planteaba el interrogante de precisar el alcance de la expresión "cualquier controversia", esto es, si incluye todas las que pueden presentarse en cualquier área, asunto o materia o, únicamente las relativas a la interconexión. Una aplicación extendida implicaría que la Autoridad de Telecomunicacio-

65 Sus artículos 33 y 34, disponen: "Art. 33. Ninguna controversia, conflicto o incumplimiento de los operadores de redes públicas de telecomunicaciones que se interconecten, podrá dar lugar a la desconexión, salvo que la Autoridad de Telecomunicaciones competente disponga lo contrario, en cuyo caso deberá dictar las medidas previas que se aplicarán con la finalidad de minimizar los efectos negativos para los usuarios de una o ambas redes. En todo caso, la interconexión sólo podrá ser interrumpida o terminada, previa autorización de la Autoridad de Telecomunicaciones competente del país donde se realiza la interconexión, de conformidad con las causales establecidas en los correspondientes acuerdos de interconexión o en su legislación interna. Art. 34. Si transcurrido el plazo previsto en el artículo 13 las partes no llegan a un acuerdo o la Autoridad de Telecomunicaciones competente del País Miembro donde se realiza la interconexión no aprueba las condiciones del mismo, ésta podrá, de oficio o a solicitud de cualquiera de las partes, fijar las condiciones de la interconexión, de acuerdo con la normatividad andina y el procedimiento establecido en su legislación interna. La Autoridad de Telecomunicaciones competente deberá pronunciarse en un plazo máximo de noventa (90) días calendario, contados a partir de la fecha en que se solicite la aprobación o se inicie el procedimiento administrativo" 
nes, sería competente para resolver todas las controversias que se presenten, incluso en asuntos constitucionales o de toda clase. Sin embargo, el precepto refería a "la Autoridad de Telecomunicaciones competente del país donde se realiza la interconexión" y a controversias surgidas durante la ejecución de la interconexión, es decir, remitía a la competencia de acuerdo a las normas internas del país y a controversias por causa u ocasión de la interconexión, lo que es consonante con el artículo 32 de la Decisión 469 de 1999.

El Tribunal de Justicia de la Comunidad Andina, en sus iniciales interpretaciones prejudiciales consideró que la norma asigna competencia privativa a la Autoridad de Telecomunicaciones para decidir las controversias surgidas durante la ejecución de la interconexión, al principio limitadas a la "interconexión"66, posteriormente extendidas a la ejecución del contrato ${ }^{67}$, y ahora al "modular" sus pronunciamientos, precisó:

66 Comunidad Andina de Naciones. Tribunal de Justicia de la Comunidad Andina. Interpretación Prejudicial 181-IP-2013:" El Tribunal entiende que en cuestiones de ejecución de la interconexión, estamos frente a una antinomia en el mismo cuerpo normativo. Esto se resuelve a la luz del principio de especialidad, el artículo 32 de la Resolución 432 se encuentra en el capítulo IV, denominado "Solución de Controversias", mientras que el artículo 17 literal f) se encuentra en el capítulo I, denominado "Generales". Como el artículo 32 es especial frente al 17 literal f), evidentemente el aplicable es el primero, esto quiere decir que todo lo relacionado con conflictos que surjan en la "ejecución de la interconexión", es de competencia exclusiva de la Autoridad de Telecomunicaciones respectiva(...). Las controversias anteriores a dicha ejecución pueden solucionarse de conformidad con el mecanismo que las partes adopten". En el mismo sentido, Comunidad Andina de Naciones. Tribunal de Justicia de la Comunidad Andina. Interpretación Prejudicial 261-IP-2013: “El Tribunal entiende que en cuestiones de ejecución de la interconexión, estamos frente a una antinomia en el mismo cuerpo normativo. Esto se resuelve a la luz del principio de especialidad, el artículo 32 de la Resolución 432 se encuentra en el capítulo IV, denominado "Solución de Controversias", mientras que el artículo 17 literal f) se encuentra en el capítulo I, denominado "Generales". Como el artículo 32 es especial frente al 17 literal f), evidentemente el aplicable es el primero, esto quiere decir que todo lo relacionado con conflictos que surjan en la "ejecución de la interconexión", es de competencia exclusiva de la Autoridad de Telecomunicaciones respectiva. Las controversias anteriores a dicha ejecución pueden solucionarse de conformidad con el mecanismo que las partes adopten".

67 Comunidad Andina de Naciones. Tribunal de Justicia de la Comunidad Andina. Interpretación Prejudicial 79-IP-2014: "El Tribunal considera importante ahondar un poco más en la siguiente cuestión: ¿cuándo tiene competencia la Autoridad de Telecomunicaciones para la solución de controversias en materia de telecomunicaciones?: Cuando estemos en frente de cualquier controversia en la "ejecución de la interconexión", es decir, cuando se esté poniendo en práctica el contrato de interconexión. Cuando se habla de cualquier controversia se debe entender en relación con asuntos o temas incluidos en el contrato, o que aunque no se incluyan en el mismo se desprendan de él, o se presenten con ocasión de la ejecución del contrato. Esto quiere decir que la competencia de la autoridad en telecomunicaciones no se da únicamente en relación con los asuntos contenidos en los artículos 16, 17 y 19 de la Resolución 432, sino de cualquier otro tema que se desprenda del contrato al ser ejecutado, o de situaciones que se presenten o se desprenda de su propia puesta en marcha. Cuando las partes en conflicto no hayan podido llegar a un acuerdo 
"2.2. En primer lugar, debe tenerse presente que de conformidad con lo establecido en el Articulo 32 de la Decisión 462 de la Comisión de la Comunidad Andina, si un proveedor que solicita una interconexión considera que es objeto de actuaciones que violan las normas o los principios de interconexión o de la libre competencia, recurrirá ante las Autoridades Nacionales respectivas de la materia que se trate, las cuales resolverán de acuerdo con su normativa nacional.

2.3. Queda claro, a partir de dicho artículo, que las actuaciones que impliquen violaciones de las normas o los principios de interconexión, así como las violaciones a la libre competencia, son de competencia de las autoridades nacionales respectivas. Y esto es así porque corresponde a las autoridades administrativas competentes salvaguardar, mediante el ejercicio de sus potestades públicas, las normas y principio de orden público y la protección de los intereses generales.

2.4. El literal f) del artículo 17 de la Resolución 432 establece que tanto los Acuerdos de Interconexión Negociados como las Ofertas Básicas de Interconexión deben contener una cláusula relativa a los mecanismos para la resolución de controversias relacionadas con la interconexión.

2.5. De esta manera, el Tribunal modula su jurisprudencia anterior manifestando que, si en la relación contractual surgen controversias relacionadas con derechos disponibles o de libre disponibilidad, como aquellos que pueden ser objeto de renuncia, cesión, modificación o extinción, debidamente permitidos por la ley y conforme a la voluntad de las partes podrán resolverlas mediante los mecanismos de solución de controversias previstos en el contrato y aprobados por la autoridad competente, de conformidad con el literal f) del Artículo 17 de la Resolución 432, entre ellos el arbitraje.

2.6. En cambio, las controversias relacionadas con derechos no disponibles, como las materias de orden público, derecho de imperio del Estado y las potestades regulatorias de la Autoridad de Telecomunicaciones, no pueden ser materia de arbitraje, por lo que, ellas tendrán que ser resueltas por la autoridad administrativa

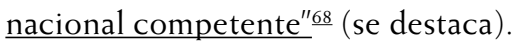

directo para la solución de la controversia. Esto quiere decir que es un requisito de procedibilidad intentar el arreglo directo antes de acudir a la autoridad competente. Esto se debe demostrar con cualquier medio de prueba aceptado por la normativa procesal interna. Se desprende de lo dicho, que las partes pueden pactar formas de solución de controversias en relación con conflictos que surjan antes de la ejecución del contrato. Por ejemplo, si el contrato no se pudo ejecutar por incumplimiento de alguna de las partes, dicha situación puede ser dirimida mediante el mecanismo estipulado; pero una vez en ejecución el contrato la competencia es exclusiva y excluyente de la Autoridad de Telecomunicaciones competente".

68 Comunidad Andina de Naciones. Tribunal de Justicia de la Comunidad Andina. Interpretación Prejudicial 366-IP-2015, reiterada en Interpretaciones Prejudiciales 385-IP-2015 y $560-$ IP-2016. 
Esta interpretación prejudicial adoptada igualmente bajo la redacción primaria del artículo 32 de la Resolución 432, no sólo se muestra coherente con el Derecho Comunitario Andino, la organización política y distribución de competencias constitucionales y legales en cada Estado miembro, sino que corrige el impacto de las precedentes interpretaciones prejudiciales en los ordenamientos jurídicos internos, en especial, en los procesos y actuaciones judiciales.

La Resolución 1922 de 2017 de la Secretaria General de la Comunidad

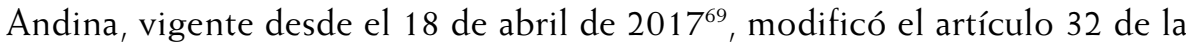
Resolución 432, así:

"Artículo 32.- Conforme a lo previsto en el literal f) del artículo 17 y sin perjuicio de lo previsto en el ordenamiento jurídico comunitario andino, cualquier controversia que surja durante la ejecución de la interconexión se tratará de resolver entre las partes.

Si dichas partes no logran un entendimiento que ponga fin a la controversia, cualquiera de ellas podrá solicitar a la autoridad del País Miembro en donde se realiza la interconexión que se encuentre facultada al efecto por su legislación interna, que la resuelva conforme a los plazos y procedimientos dispuestos en dicha legislación.

En cualquier caso, la decisión que adopte la señalada autoridad deberá ser conforme con el ordenamiento jurídico comunitario andino." (se subraya).

\section{LA JURISPRUDENCIA CONSTITUCIONAL RESPECTO DEL ALCANCE DEL DERECHO COMUNITARIO ANDINO Y LAS INTERPRETACIONES PREJUDICIALES DEL TRIBUNAL DE JUSTICIA DE LA COMUNIDAD ANDINA}

La jurisprudencia constitucional caracteriza las normas comunitarias andinas consagradas en los tratados o convenios internacionales de integración o emanadas de los órganos comunitarios, por su "presunción de validez", "supranacionalidad", "autonomía", "preeminencia", "prevalencia" o "primacía" sobre las normas legales internas reguladoras de idéntica materia que son "desplazadas", eficacia o aplicación directa e inmediata y complemento necesario o indispensable, en un régimen jurídico de derecho internacional, armónico, homogéneo y vinculante ${ }^{70}$.

69 Gaceta Oficial del Acuerdo de Cartagena n. ${ }^{\circ}$ 2989, año XXXIV. Lima 18 de abril de 2017. Disponible en: http://intranet.comunidadandina.org/Documentos/Gacetas/GACE2989.pdf

70 Corte Suprema de Justicia, sentencia del 27 de febrero de 1975, Gaceta Judicial, T. 152 153, n. ${ }^{\circ} 2393-2394,1975$, p. 29. Corte Constitucional, Sentencias C-225-95, C-137-96, C-231-97, C-256-98, C-227-99, C-1490-00, C-644-04, C-269-14. En Sentencia C-228 de 1995, anota: "[...] un sistema preeminente o de aplicación preferencial frente al derecho interno de cada país miembro y con una capacidad de aplicación directa y eficacia 
En forma consistente, ha destacado:

(i) El Derecho Comunitario Andino no integra el "bloque de constitucionalidad" (arts. $9^{\circ}, 53,93,94,102,214$ Constitución Política) $)^{71}$, al no referir a derechos humanos, leyes orgánicas, estatutarias ni tratados limítrofes ${ }^{72}$ sino a derechos de contenido económico, y sólo lo integrarían cuando en forma explícita reconozcan o desarrollen derechos humanos, "de donde surge que una prevalencia del derecho comunitario andino sobre el orden interno, similar a la prevista en el artículo 93 de la Carta, carece de sustento" 73 .

inmediata". Consejo de Estado, Sala de lo Contencioso Administrativo, Sección Tercera, Sala Plena. Sentencia de 9 de agosto de 2012, Radicación 11001032600020120001800 (43.195); Sentencia de 9 de agosto de 2012, Radicación 11001032600020120002000 4(43281); Sentencia de 9 de agosto de 2012, Radicación 11001032600020120001300 (43045) y, Sección Tercera, Subsección A, sentencia de noviembre 21 de 2012. Radicación: 11001032600020100005600 (39.373: "principales características del Derecho Comunitario

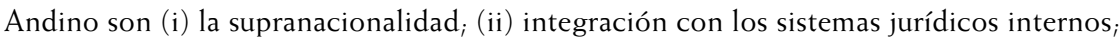
(iii) la aplicabilidad y efectos directos o inmediatos y (iv) su intangibilidad y autonomía."

71 Corte Constitucional, Sentencias C-574 de 1992, C-295 de 1993, C-225 de 1995, C-578 de 1995, C-358 de 1997, C-191 de 1998, C-1022 de 1999, C-067 de 2003, C-028 de 2006, C-271 de 2007, C-664 de 2013, C-458 de 2015, C-025 de 2016, C-327 de 2016.

72 Corte Constitucional, Sentencias C-337 de 1993, C-423 de 1995, C-578 de 1995, C-287 de 1997, C-358 de 1997, C-191 de 1998, C-582 de 1999, C-774-01, C- 708 de 1999.

73 Corte Constitucional, Sentencia C-256 de 1998: "Ni los tratados de integración ni el derecho comunitario se acomodan a los supuestos normados por el artículo 93 constitucional, ya que sin perjuicio del respeto a los principios superiores del ordenamiento constitucional destacado en la citada sentencia n. ${ }^{\circ} \mathrm{C}-231$ de 1997, su finalidad no es el reconocimiento de los derechos humanos sino la regulación de aspectos económicos, fiscales, aduaneros, monetarios, técnicos, etc., de donde surge que una prevalencia del derecho comunitario andino sobre el orden interno, similar a la prevista en el artículo 93 de la Carta, carece de sustento. Así pues, vistas las cosas a partir del artículo 93, el derecho comunitario andino no conforma el bloque de constitucionalidad y, por ende, tampoco comparte la supremacía de la Carta Fundamental frente a la ley [...] Sirven los anteriores argumentos al propósito de demostrar que no existe la superioridad del derecho comunitario sobre la Constitución, y que no es cierto que comparta con ella idéntica jerarquía. Adicionalmente, el derecho comunitario tampoco conforma un cuerpo normativo intermedio entre la Carta Fundamental y la ley ordinaria, [...]". Sentencia C-988 de 2004: "Ahora bien, específicamente sobre las normas comunitarias, la Corte ha considerado que la regla general es que ni los tratados de integración económica ni el derecho comunitario integran el bloque de constitucionalidad, como quiera que su finalidad no es el reconocimiento de los derechos humanos sino la regulación de aspectos económicos, sociales, aduaneros, monetarios, técnicos, etc., de donde surge que una prevalencia del derecho comunitario andino sobre el orden interno, similar a la prevista en el artículo 93 de la Carta, carece de sustento (...) Con todo, de manera excepcionalísima, la Corte ha admitido que algunas normas comunitarias pueden integrarse al bloque de constitucionalidad, siempre y cuando se trate de una norma comunitaria que de manera explícita y directa reconozca y desarrolle derechos humanos". Sentencia C-339 de 2006. [... ]una prevalencia del derecho comunitario andino sobre el orden interno, al tenor de lo previsto en el artículo 93 de la Carta, carece de fundamento, Sin embargo, de manera excepcional ha admitido la Corte que algunas normas 
(ii) No tienen idéntica jerarquía a las normas constitucionales, carecen de supremacía, superioridad o prevalencia sobre la Constitución Política, sus principios y valores, salvo exigencia de norma expresa se incorporan al Derecho Interno de cada país desde su promulgación, y prevalecen sobre el derecho interno, no por derogación sino por desplazamiento.

(iii) Al comportar una transferencia de competencias soberanas e imponer obligaciones a los Estados, deben acatarse y aplicarse por las autoridades internas, más en ningún caso a contrariedad de "los principios superiores del ordenamiento constitucional - respeto de los derechos bumanos, vigencia del Estado Social de Derecho, de la democracia y de la separación de poderes" ${ }^{174}$, de "suerte que, si el contenido de un acuerdo de integración desconoce el principio de soberanía popular, la dignidad del bombre y los derechos y libertades fundamentales, o los mandatos, valores y principios del Estado Social de Derecho, no podría superar el test de constitucionalidad"75.

(iv) Corresponde a los jueces y operadores jurídicos encargados de resolver los conflictos concretos apreciar las eventuales contradicciones entre las

comunitarias puedan integrarse al bloque de constitucionalidad, siempre y cuando se trate de normas de esta naturaleza que de manera explícita y directa reconozcan y desarrollen derechos humanos"..

74 Corte Constitucional, Sentencia C-231-97: "9.[... . Dado que el acuerdo ha significado la transferencia de competencias soberanas por parte de los Estados a las autoridades supranacionales, un amplio número de decisiones comunitarias se aplican directamente en los países signatarios y otras surten efectos internos luego de agotado su proceso de incorporación. [...] Queda claro que si no se descubre el modo de impedir que al menos los principios superiores del ordenamiento constitucional - respeto de los derechos humanos, vigencia del Estado social de derecho, de la democracia y de la separación de poderes -, se preserven en la fase de ejecución del acuerdo, los órganos de la comunidad detentarían un poder constituyente que ninguno de los países imaginó conferirles. Sin embargo, esta hipótesis debe desecharse puesto que el desarrollo del tratado, en modo alguno, requiere que dichos principios dejen de observarse. Las facultades de las autoridades de la subregión se limitan al ejercicio de las competencias que se trasladan a la comunidad y éstas, como emanación de los diferentes pueblos soberanos, no comportan la posibilidad de quebrantar tales principios que, además de corresponder a la tradición de los países firmantes, se recogen en los tratados internacionales suscritos por ellos y que, por su condición de derecho imperativo, resultan oponibles y vinculantes en el seno de la comunidad creada. No cabe la menor duda de que los actos y decisiones comunitarias que violen los principios superiores deben reputarse ultra vires y ser anulados por denotar desviación de poder. En este sentido corresponderá al Tribunal de Justicia del Acuerdo de Cartagena, conforme a las disposiciones del tratado que lo constituyó, declarar la nulidad de las decisiones de la comunidad que violen el ordenamiento jurídico de la comunidad, dentro del cual deberán entenderse incorporados los expresados principios superiores. $\mathrm{Ni}$ las partes signatarias al dar vida al acuerdo abdicaron de tales principios, ni los tratados internacionales que en punto a los derechos humanos y a su efectiva protección se encuentran vigentes, permiten o toleran que al socaire de tratados de integración se pretenda desconocer su obligatoriedad". 
normas comunitarias e internas, a quienes igualmente compete determinar su aplicación en el caso concreto ${ }^{76}$.

La interpretación prejudicial "debe tenerse en cuenta si el juez nacional considera que la normatividad comunitaria es aplicable", pero "de ninguna manera es una forma de predeterminar el fallo sobre las normas internas", su solicitud se formula "en virtud de su posible aplicación", su "alcance es restringido" y no determina que "necesariamente" deban aplicarse las normas andinas, lo que define el juez nacional ${ }^{77}$.

(v) El juez constitucional ante la denegación de justicia del Tribunal o la probada ineficacia de sus mecanismos para infirmar las decisiones o actos de la comunidad violatorias de los derechos humanos u otro principio jurídico superior, podrá en caso extremo, ordenar su inaplicación interna:

"Debe en todo caso plantearse el interrogante teórico sobre el curso de acción que habrá de seguirse si una norma o decisión dictada en desarrollo del acuerdo, viola un principio superior.

76 Corte Consitucional, Sentencia C-228-1995: "Como se desprende de las disposiciones transcritas, la solución del caso planteado implica, de una parte, la consideración de la normatividad comunitaria y de la interpretación que de ella haga el citado Tribunal y, de otra, el juicio de constitucionalidad que debe hacer la Corte con respecto a las normas demandadas. Es decir, nos hallamos en presencia de una particular colaboración entre el juez nacional y el juez comunitario, aun cuando ambos actúen en ámbitos jurisdiccionales diferentes, en la aplicación de normas que tienen distinto contenido de validez, pero que exigen una interpretación integral. No existe, por tanto superposición de una jurisdicción sobre otra, que pudiera dar lugar a la estructura de una jerarquía, sino mas bien actuaciones jurisdiccionales complementarias e interactuantes de los jueces comunitarios y nacionales que permiten la aplicación uniforme del derecho comunitario, e igualmente conciliada con el derecho nacional. Aparece delimitada la función del Tribunal Andino de Justicia y de este Corte, con respecto a la elucidación del asunto a que se contrae la demanda, así: corresponde al Tribunal hacer la interpretación prejudicial de las aludidas normas comunitarias, limitándose a precisar el contenido y alcance de las mismas, sin interpretar el aspecto sustancial del derecho nacional ni calificar los hechos materia del proceso, pues esto último corresponde a la Corte. Dentro de los supuestos limitativos anotados, la Corte debe acatar la interpretación prejudicial hecha por el Tribunal". (se subraya)

77 Corte Consitucional, Auto n. ${ }^{\circ}$ 054-04, Exp. D-4884:"10.- Cabría entonces la pregunta sobre la fuerza vinculante de tal decisión, pues podría asumirse que el Tribunal de Justicia de la Comunidad Andina desplazaría a la Corte. Sobre esta conclusión, la Corte Constitucional ya se ha pronunciado para aclarar que se trata de una inferencia equivocada. Así, en un caso anterior conocido por la Corte, también fue solicitada la interpretación prejudicial del Tribunal de Justicia de la Comunidad Andina por las mismas razones que en este caso se ha hecho la solicitud. En aquella ocasión, la sentencia C-228 de 1995 aclaró el punto de la supuesta superposición de jurisdicciones para concluir que se estaba en presencia de una especial colaboración entre el juez nacional y el comunitario. Así, este fallo determinó que debía ser considerada la normatividad comunitaria y la interpretación del Tribunal sobre ella. [...] El pronunciamiento anterior no deja duda alguna sobre cuál es el alcance de la eventual obligación que pesa sobre la Corte Constitucional de acatar la interpretación prejudicial hecha por el Tribunal de Justicia de la Comunidad Andina. Incluso, éste ha establecido que sus conceptos no vinculan a los jueces nacionales para proferir fallos donde determinen asuntos específicos de su derecho interno". 
La independencia y autonomía del derecho comunitario, se ha querido preservar en este trance merced a la obligada intervención que se reserva al Tribunal de Justicia del Acuerdo, el cual a instancia de cualquier país miembro, de un órgano del sistema o de la persona natural o jurídica perjudicada, deberá anular el acto que quebrante el derecho comunitario, incluso por desviación de poder, el que sin duda se presenta cuando quiera se desacatan los principios superiores (Ley 17 de 1980, art. 17-20)

La denegación de justicia por parte del Tribunal o la probada ineficacia de sus mecanismos judiciales para enervar las decisiones o actos de la comunidad que violen los derechos humanos u otro principio jurídico superior, podría eventualmente llevar a la Jurisdicción Constitucional, en una situación extrema, a ordenar su inaplicación interna, siempre que previamente se hubiere procurado obtener del Tribunal Andino la interpretación de la norma sobre cuya aplicación se centra la controversia (Ley 17 de 1980 art. 29).

En este evento cabe distinguir la validez de la decisión comunitaria que es asunto ajeno al órgano judicial nacional, de la inaplicación interna en un caso particular y por el motivo expresado". ${ }^{78}$

\section{LA JURISPRUDENCIA ADMINISTRATIVA RESPECTO DEL ALCANCE DEL DERECHO COMUNITARIO ANDINO Y LAS INTERPRETACIONES PREJUDICIALES DEL TRIBUNAL DE JUSTICIA DE LA COMUNIDAD ANDINA}

La jurisprudencia del Consejo de Estado en forma reiterada, clara, precisa e inalterada en consonancia con el orden jurídico interno y los fallos de constitucionalidad de la Corte Constitucional, sostuvo la jurisdicción y competencia de los jueces permanentes o arbitrales para decidir los conflictos entre operadores de telecomunicaciones diferentes a los asignados a la autoridad regulatoria dentro del marco de sus competencias administrativas y de la regulación.

Para cumplir órdenes impartidas por el Tribunal de Justicia de la Comunidad Andina ${ }^{79}$, las sentencias pronunciadas el 9 de agosto de 2012 por la Sala

78 Cfr. Corte Constitucional, Sentencia C-231-97.

79 Comunidad Andina de Naciones. Tribunal de Justicia de la Comunidad Andina. Proceso 03-AI-2010, Acción de incumplimiento contra la República de Colombia, Sentencia de 26 de agosto de 2011: "En virtud de lo expuesto: "EL TRIBUNAL DE JUSTICIA DE LA COMUNIDAD ANDINA: DECIDE: "Primero: Declarar a lugar la demanda interpuesta por la Empresa [de] Telecomunicaciones de Bogotá S.A. ETB S.A. E.S.P., contra la República de Colombia, a través de la Sección Tercera del Consejo de Estado, por no haber solicitado oportunamente interpretación prejudicial dentro del proceso de anulación de tres (03) laudos arbitrales, de acuerdo a lo sentado por este Tribunal en la parte considerativa de la presente sentencia. Debe en consecuencia, la República de Colombia proceder conforme lo establece el artículo 111 de la Decisión 500 de la Comisión de la Comunidad Andina, a dar cumplimiento 
Plena de la Sección Tercera del Consejo de Estado ${ }^{80}$, dejaron sin efectos las proferidas el 27 de marzo de 2008 y el 21 de mayo de 2008 que declararon infundados los recursos de anulación contra los laudos arbitrales recurridos ${ }^{81}$.

Luego de advertir el Consejo de Estado que "no puede el órgano interno so pretexto de una norma o decisión comunitaria andina desconocer, desbordar o quebrar las garantías mínimas consagradas en la Constitución Política o en los Tratados Internacionales de respeto a los derechos bumanos de todos los sujetos", instituyó una causal de anulación consistente "en la omisión del deber de solicitar la Interpretación Prejudicial de las normas comunitarias andinas aplicables al caso, por parte del Tribunal de Arbitramento que tenga conocimiento del mismo", estimó "que es su deber efectuar una interpretación razonable de las decisiones comentadas, consultando básicamente el ordenamiento constitucional colombiano como los principios

a esta sentencia". En decisión del 15 de noviembre de 2011, decidió: "Primero: No ha lugar a la enmienda de la Sentencia de 26 de agosto de 2011, dictada dentro del Proceso 03-AI2010, solicitada por la República de Colombia. "Segundo: Sí ha lugar a la aclaración de la Sentencia de 26 de agosto de 2011, dictada dentro del Proceso 03-AI-2010, solicitada por la República de Colombia, de acuerdo a la parte considerativa del presente auto, en especial la relacionada con las acciones que debe adelantar el H. Consejo de Estado de la República de Colombia, Sección Tercera". [... ] en consecuencia, debe el Consejo de Estado de la República de Colombia, Sección Tercera, realizar las siguientes acciones: De conformidad con las previsiones del derecho procesal interno colombiano, dejar sin efecto las providencias que resolvieron los recursos de anulación. [...] Que, ahora bien, la interpretación de las normas sobre la Decisión 462 de la Comisión de la Comunidad Andina, se establecerá una vez que el Tribunal de Arbitramento se constituya nuevamente de acuerdo con las normas colombianas y éste solicite la debida interpretación prejudicial de conformidad con la normativa comunitaria y la jurisprudencia del Tribunal de Justicia de la Comunidad Andina". En decisión de 18 de julio de 2012, aclara los alcances de su decisión:"Que, para dar cabal cumplimiento a la sentencia a la sentencia de 26 de agosto de 2011, la República de Colombia a través de la Sección Tercera del Consejo de Estado, debe realizar las siguientes acciones: "Proceder a declarar la nulidad de todo lo actuado desde el momento en que surgió la obligación para el Consejo de Estado de solicitar la interpretación prejudicial, es decir, antes de la emisión de las providencias que resolvieron los recursos de anulación. "Continuar el proceso tomando la Sentencia de 26 de agosto de 2011, expedida en el marco del proceso de incumplimiento 03-AI-2010, como la interpretación prejudicial que debió solicitar el Consejo de Estado. Esta providencia, por economía procesal, se debe tomar como la interpretación prejudicial que fija el sentido y alcance de los artículos 33 del Tratado de Creación del Tribunal de Justicia de la Comunidad Andina y 122 y 123 de su Estatuto. "Anular los laudos arbitrales y, como efecto, devolver el asunto al Tribunal de Arbitramento que debió solicitar la consulta prejudicial, para que, de conformidad con los mecanismos procesales aplicables, subsane su omisión y emita un nuevo laudo, acogiendo, para tal fin, la providencia que expida en su momento el Tribunal de Justicia de la Comunidad Andina".

80 Consejo de Estado, Sala de lo Contencioso Administrativo, Sección Tercera, Sala Plena. Radicación n. ${ }^{\circ}$ 11001-03-26-000-2012-00020-00(43281),Radicación n. ${ }^{\circ}$ 11001-03-26000-2012-00018-00 (43.195) y Radicación n. ${ }^{0} 11001-03-26000-2012-00013-00$ (43.045).

81 Consejo de Estado, Sala de lo Contencioso Administrativo, Sección Tercera, sentencia de 21 de mayo de 2008, Radicación n. ${ }^{\circ}$ : 0001-03-26-000-2007-00008-00(33.643); sentencia de 27 de marzo de 2012, Radicación n. $.^{\circ}: 1$ 1001-03-26-000-2007-00009-00(33.644) y sentencia de 27 de marzo de 2012, Radicación n. ${ }^{\circ}:$ 11001-03-26-000-2007-00010-01 (33.645). 
que lo informan, el cual -según se explicó ampliamente- en modo alguno resulta desplazado o modificado por el ordenamiento andino que, bueno es precisarlo, no contiene regulación positiva alguna acerca del régimen arbitral aplicable en la subregión", para puntualizar:

"Así las cosas y, se insiste, con el fin de alcanzar la mejor, la más razonable y la más coberente interpretación posible a las decisiones del Tribunal de Justicia de la Comunidad Andina en el presente caso, para efectos de asegurar su efectivo y adecuado cumplimiento, la Sala entiende que, como bien lo expresó el auto aclaratorio del propio Tribunal de Justicia de la Comunidad Andina en noviembre 15 de 2011, después de anulado el laudo sólo procedería -cuestión que consulta perfectamente el ordenamiento constitucional y legal colombiano- la convocatoria de un nuevo Tribunal de Arbitramento, convocatoria que debería efectuarse con sujeción a las normas que regulan la materia, nuevo Tribunal de Arbitramento que tendría, por tanto, el deber de satisfacer la exigencia impuesta por el ordenamiento andino en el sentido de solicitar la Interpretación Prejudicial que resulta imperativa en el caso sub examine para que, posteriormente, con apoyo en dicha Interpretación Prejudicial y de baber lugar a ello, se profiera el correspondiente laudo arbitral".

En sentencia del 21 de noviembre de 2012, al omitirse la interpretación prejudicial anuló un laudo arbitral "por la causal de anulación derivada de la inobservancia de la obligación impuesta por el Derecho Comunitario Andino a los jueces nacionales de solicitar al Tribunal de Justicia de la comunidad la interpretación Prejudicial de las normas comunitarias aplicables al caso que resuelven" reiterando las sentencias del 9 de julio de $2012^{82}$. Asímismo decidió en sentencia del 10 de noviembre de $2016^{83}$.

En sentencias del 23 de septiembre de $2015^{84}$ y 3 de agosto de $2016^{85}$ declaró infundados los recursos en contra de los laudos arbitrales que decidieron su no

82 Consejo de Estado, Sala de lo Contencioso Administrativo, Sección Tercera, Subsección A, Sentencia de 21 de noviembre de 2012, Radicación n. ${ }^{\circ}$ 11001-03-26-000-201-00005600 (39373).

83 Consejo de Estado, Sala de lo Contencioso Administrativo, Sección Tercera, Subsección C, Sentencia de 10 de noviembre de 2016, Radicación nº 11001-03-26-000-2016-00063$00(56845)$,

84 Consejo de Estado, Sala de lo Contencioso Administrativo, Sección Tercera, Subsección A Sentencia de 23 de septiembre de 2015, Radicación Número 11001032600020150001800 (53.054). Indicó el Consejo de Estado que, según la interpretación prejudicial, la competencia de la Autoridad "de comunicaciones para resolver los conflictos entre los proveedores de redes y servicios de comunicaciones está dada por la materia 'conflictos de interconexión' [...] El pronunciamiento del Tribunal de Justicia de la Comunidad Andina es claro: los conflictos surgidos entre operadores por temas atinentes a la interconexión deben ser resueltos por la autoridad nacional competente del país donde se realiza la interconexión, que en Colombia es la CRC, en los términos del artículo 22 (numeral 9) de la Ley 1341 de 2009,[... En este sentido, debe entenderse, a la luz de la interpretación prejudicial emitida por el Tribunal de Justicia de la Comunidad Andina en el marco del proceso arbitral que terminó con el laudo objeto del recurso, que cualquier conflicto de interconexión entre operadores de redes y servicios de comunicaciones es de competencia de la autoridad nacional de comunicaciones del país donde se presta el servicio, que en el caso de Colombia es la CRC." (se subraya).

85 Consejo de Estado, Sala de lo Contencioso Administrativo, Sección Tercera, Subsección

REVIST@ E-MERCATORIA, VOL. 17 N.1, ENERO-JUNIO/2018, PP. 3-45 
competencia para conocer del asunto conforme a la interpretación prejudicial del Tribunal de Justicia de la Comunidad Andina y ordenó remitir los asuntos a la Comisión de Regulación de Comunicaciones. Antes de la sentencia de 23 de septiembre de 2015, el Consejo de Estado distinguía la competencia de la Autoridad Reguladora para resolver conflictos de telecomunicaciones, de la jurisdicción y competencia de los jueces. La competencia de la Comisión de Regulación estaba restringida a sus competencias administrativas y a la regulación, sin incluir conflictos contractuales o ajenos a la regulación.

En sentencias de 2 de diciembre de $2015^{86} ; 24$ de noviembre de $2016^{87}, \mathrm{y}$ 7 de diciembre de 2017, con las interpretaciones prejudiciales del Tribunal de Justicia de la Comunidad Andina que concluyen la competencia de la Autoridad de Telecomunicaciones para conocer de "cualquier conflicto durante la ejecución de la interconexión", incluidos los contractuales, declaró fundados los recursos, anuló los laudos y ordenó remitir los asuntos a la Comisión de Regulación de Comunicaciones ${ }^{88}$.

De su parte, la Sala de Consulta y Servicio Civil del Consejo de Estado, en concepto rendido al Gobierno Nacional el 24 de octubre de 2016, señaló lo siguiente:

(i) La competencia administrativa de la Comisión de Regulación de Comunicaciones para resolver controversias entre proveedores de redes y servicios de telecomunicaciones se asigna "por el artículo 32 de la Decisión 462, con expresa remisión a la "normativa nacional" para su ejercicio, en armonía con las disposiciones pertinentes de la Resolución 432" 89.

(ii) Está limitada "al ámbito de sus competencias regulatorias en materia de interconexión, vinculadas al interés general de la regulación, en concordancia con el objeto asignado a la $C R C$, restricción que no solo es contemplada en nuestra legislación sino que se registra también

C, Sentencia de 3 de agosto de 2016, Radicación n. ${ }^{\circ}$ 11001-03-26-000-2015-00089-00 (54.315).

86 Consejo de Estado, Sala de lo Contencioso Administrativo, Sección Tercera, Subsección A, Sentencia de 2 de diciembre de 2015, Radicación n. ${ }^{\circ} 110010326000201500030-00$ (53.182). Según la transcripción de la sentencia, el laudo arbitral distinguió los "conflictos de interconexión" o "durante la ejecución de la interconexión" competencia de la Autoridad Regulatoria, de los distintos a la "ejecución de la interconexión", competencia del juez natural.

87 Consejo de Estado, Sala de lo Contencioso Administrativo, Sección Tercera, Subsección C, Sentencia de 24 de noviembre de 2016, Radicación n. ${ }^{\circ}$ 11001-03-26-000-2015-00089$00(54.315)$

88 Consejo de Estado, Sala de lo Contencioso Administrativo, Sección Tercera, Subsección B, Sentencia de 7 de diciembre de 2017, Radicación n. ${ }^{\circ} 11001032600020140017200$ (52.741).

89 Consejo de Estado, Sala de Consulta y Servicio Civil, Concepto 2293 de octubre 24 de 2016, Rad. 2293, N. ${ }^{\circ}$ único 11001-03-06-000-2016-00074-00, adoptado por los Magistrados Germán Alberto Bula Escobar, presidente de la Sala-Oscar Dario Amaya Navas—Luis Fernando Álvarez Jaramillo (conjuez). 
en el derecho comparado" y comprende sólo las controversias correspondientes al "marco de competencias regulatorias en materia de interconexión" 90.

"[...]

b) En concordancia con el citado objeto, el artículo 22 de la Ley 1341 dispone que la CRC debe expedir "toda" la regulación de carácter general y particular respecto de las siguientes materias:

i) Los aspectos técnicos y económicos relacionados con la obligación de interconexión y el acceso y uso de instalaciones esenciales, recursos físicos y soportes lógicos necesarios para la interconexión;

ii) La remuneración por el acceso y uso de redes e infraestructura, precios mayoristas, las condiciones de facturación y recaudo;

iii) El régimen de acceso y uso de redes;

iv) Los parámetros de calidad de los servicios de interconexión, y

v) régimen de competencia en materia de interconexión.

Como puede deducirse, las materias precitadas a las que alude el artículo 22 de la Ley 1341 de 2009, involucran intereses superiores y no se pueden abandonar a la autonomía de la voluntad privada ni al libre juego del mercado, razón por la que legalmente se enmarcan en el campo de la intervención del Estado a través de las competencias de regulación económica, mediante el instrumento de solución de controversias atribuido a la CRC.

Así las cosas, la zona de certeza positiva respecto de las controversias que en ejecución de los acuerdos (contratos) de interconexión puede conocer la CRC, corresponde a los asuntos señalados en el literal b) precedente, los cuales se relacionan directamente con el marco de competencias en materia de interconexión asignado a la CRC." ${ }^{91}$.

(iii) Las diferencias "que solo involucran el interés privado y patrimonial de las partes de un acuerdo de interconexión", "no son de competencia de la CRC en ejercicio de la función de solución de controversias previstas en el numeral go del artículo 22 de la Ley 1341 de 2009":

"En este sentido, sin perjuicio de las normas de derecho público que rigen la actividad de los proveedores en el sector de las tecnologías de la información y las telecomunicaciones, entre las cuales se destaca la regulación (en su acepción de potestad normativa) proferida por la CRC, el régimen de actos y contratos de tales proveedores corresponde al derecho privado por expresa disposición del artículo 55 de la Ley 1341 de 2009, por lo que los conflictos derivados de tales actos y 
contratos que exclusivamente involucren un interés privado deben ser resueltos de conformidad con las reglas generales de solución de conflictos previstas en el ordenamiento jurídico interno.

En esta zona también se incluyen conflictos de carácter laboral derivados de contratos de trabajo y los relacionados con la responsabilidad civil contractual o extracontractual entre los proveedores de tales servicios" (Se subraya) ${ }^{92}$.

(iv) La CRC, en el marco de sus competencias al solucionar las controversias surgidas "durante la ejecución de la interconexión" puede adoptar decisiones sobre el incumplimiento o la ruptura del equilibrio económico del contrato ${ }^{93}$.

"¿Puede la CRC, en el marco de sus competencias, adoptar decisiones de fondo sobre aspectos relativos a la ejecución de los contratos de interconexión entre proveedores de redes y servicios de telecomunicaciones, al solucionar controversias que surjan 'durante la ejecución de la interconexión' como el incumplimiento o la ruptura del equilibrio económico del contrato?"

"[...] la respuesta a la pregunta es afirmativa, como regla general de competencia, máxime cuando aspectos como el mencionado equilibro financiero -del contrato de interconexión o de la relación de interconexión- son objeto de regulación por las normas comunitarias y por el derecho interno, de manera que no son expresión de la sola voluntad de las partes".

El importante concepto de la Sala de Consulta y Servicio Civil representa un notable avance.

Por supuesto, el equilibrio económico del contrato de interconexión que, como señala acertadamente el concepto "sin perjuicio de las normas de derecho público que rigen la actividad de los proveedores en el sector de las tecnologías de la información y las telecomunicaciones, entre las cuales se destaca la regulación"(art. 22, Ley 1341 de 2009), se rige por el derecho privado (art. 55 de la Ley 1341 de 2009), es materia que involucra el "interés privado" de las partes.

Distinta es la hipótesis, como acontece en otras materias similares (regímenes tarifarios, precios controlados, esquemas regulados de retribución), que al decidir un conflicto deba aplicarse la regulación, y resolver conforme a ésta, desde luego que, a la Autoridad Reguladora compete expedir las normas sobre la remuneración por el acceso y uso de redes e infraestructura, precios mayoriastas, facturación y recaudo, los aspectos técnicos y económicos de la interconexión, su régimen, términos y condiciones (art. 22, Ley 1341 de 2009), tarifas, cargos, metodología y correcciones, las normas de regulación 
son obligatorias mientras no sean suspendidas o anuladas por la jurisdicción administrativa, y no pueden modificarse sino por las autoridad reguladora.

De este modo, un desequilibrio contractual puede provenir del sistema de remuneración regulado, cuya modificación sólo corresponde a la autoridad regulatoria o por causas diferentes a las que resultan de aplicar la regulación.

\section{CONCLUSIONES}

1. El arbitraje está expresamente autorizado por la Constitución Política, en los términos que determine la ley, y la regulación normativa del recurso extraordinario de anulación del laudo arbitral, se caracteriza por su tipicidad legal, taxatividad y carácter restrictivo.

2. En el ordenamiento jurídico colombiano la función especial de resolución de conflictos de la Comisión de Regulación de Comunicaciones, únicamente puede ejercerse en el "marco de sus competencias" y en el "ambito material de la regulación", sin comprender asuntos ajenos a su facultad de intervención y estrictas competencias administrativas regulatorias.

3. Según los fallos pronunciados por la Corte Constitucional en ejercicio del control de constitucionalidad de la ley, tratados y convenios de integración, el ordenamiento jurídico andino se caracteriza por su presunción de validez, "supranacionalidad", "autonomía", "preeminencia", "prevalencia" o "primacía" sobre las normas internas, eficacia o aplicación directa e inmediata y complemento necesario o indispensable, mas no integran el "bloque de constitucionalidad", carece de superioridad o primacia sobre la Constitución Política, y no puede aplicarse a contrariedad de "los principios superiores del ordenamiento constitucional -respeto de los derechos humanos, vigencia del Estado social de derecho, de la democracia y de la separación de poderes-, u "otro principio jurídico superior", cuyo potencial quebranto "podría eventualmente llevar a la Jurisdicción Constitucional, en una situación extrema, a ordenar su inaplicación interna", esto es, no procede aplicar una norma comunitaria, interpretación prejudicial o sentencia internacional cuando conduzca a desconocer los principios superiores del ordenamiento constitucional, en particular, la separación de poderes públicos, o las competencias constitucionales y legales.

4. De acuerdo con reiterados fallos de exequilibilidad, la función de la Comisión de Regulación de Comunicaciones para resolver conflictos se ejerce "dentro del marco de las competencias" que la ley le "encomienda al órgano regulador", está circunscrita a la regulación, y no "impide que los proveedores de redes y servicios celebren pactos compromisorios respecto de asuntos en las cuales no estén involucradas las competencias de regulación legalmente atribuidas a este organismo", en cuya ausencia, corresponde por mandato constitucional, a los jueces $\mathrm{y}$, no a la Comsión, la función privativa de dirimir las controversias ajenas a la regulación y a sus competencias administrativas de intervención. 
5. La jurisprudencia administrativa hasta la sentencia del 23 de septiembre de 2015 admitió la competencia de los jueces permanentes o arbitrales para conocer de las controversias ajenas a la regulación y a la competencia administrativa de solución de conflictos asignada a las Comisiones de Regulación de los Servicios Públicos.

6. La causal de anulación de laudos arbitrales por desconocer u omitir la interpretación prejudicial no está prevista en el derecho colombiano. El origen de esta causal es jurisprudencial, y no es unánime ${ }^{94}$.

7. En efecto, el Derecho Comunitario Andino, como reconocen las sentencias de 19 de julio de 2012 del Consejo de Estado "no contiene regulación positiva alguna acerca del régimen arbitral aplicable en la subregión", y el orden jurídico interno disciplina en forma taxativa, y restringida las causales de anulación de los laudos arbitrales, sin consagrarla.Tampoco es necesaria la interpretación prejudicial para decidir un recurso extraordinario de anulación frente a laudos arbitrales, por tratarse de una materia estricta del derecho nacional interno

94 Consejo de Estado, Sala de lo Contencioso Administrativo, Sección Tercera, Subsección C, Sentencias de 3 agosto de 2016, Radicación n. ${ }^{\circ}$ 11001-03-26-000-2015-00089-00 (54.315) y de 10 de noviembre de 2016, Radicación n. ${ }^{\circ}$ 11001-03-26-000-2016-0006300 (56845), Aclaración de Voto: "1. Compete exclusivamente al legislador regular las causales de anulación de las decisiones de los árbitros (Art. 116 y 150 . num 1 y 2 C.N.). Nuestro ordenamiento no previó en la Ley 80 de 1993, tampoco en la Ley 1150 de 2007, ni recientemente en la Ley 1563 de 2012, como causal de anulación de laudos arbitrales, la omisión de "consultar" al Tribunal Andino de Justicia en aquellos eventos en los cuales se discuta la aplicación de normas comunitarias andinas. Tampoco, el ordenamiento andino contiene regulación positiva alguna acerca del régimen arbitral aplicable en la subregión, en tanto que este asunto corresponde al legislador interno. En tal virtud, vía decisión jurisprudencial no es posible crear causales y, aún menos, anular un laudo arbitral, con fundamento en situaciones no previstas la ley. 2. El entendimiento de la "causal" de anulación contraviene la naturaleza del recurso de anulación de laudo arbitral. Los supuestos que configuran la "causal de anulación", conforme la interpretación del artículo 33 de la Decisión 500 de 2001, se refieren a aquellos eventos en los que corresponda la aplicación de las normas comunitarias o cuando surge una controversia sobre dicha aplicación. Incluso, se opta por su estructuración en casos, como en el que dio origen a la decisión en este proceso, en el que la aplicación de esas normas no se discutió ni fue determinante para la decisión del proceso arbitral, pero el juez de anulación considera o, al menos, tiene dudas sobre esa circunstancia. El proceso de raciocinio que lleva a sostener que en un caso son aplicables normas comunitarias, sin que tal circunstancia fuera debatida en el proceso arbitral, supone la definición del derecho aplicable al litigio, aspecto que tiene que ver con asuntos sustanciales de la controversia. Este "causal" desconoce, entonces, los estrictos y precisos términos del recurso anulación de laudos arbitrales, pues impone al juez del recurso extraordinario definir primero el derecho aplicable, para, de allí, derivar el yerro que justifica la anulación, esto es, su no consulta al Tribunal Andino de Justicia. Así, aun cuando las características del recurso de anulación de laudos arbitrales exigen al Consejo de Estado limitarse a aspectos in procedendo, la aplicación de esta "causal" amplía el restringido ámbito de acción del juez del recurso, en cuanto funda su procedencia en errores in iudicando" 
que no versa sobre la interpretación de las normas comunitarias y debe decidir el juez nacional.

8. El Consejo de Estado en las sentencias del 9 de julio de $2012^{95}$, determinó la convocatoria de nuevo tribunal de arbitraje para conocer de las diferencias en razón de los contratos de acceso, uso e interconexión sobre las que versaron los laudos anulados ${ }^{96}$. Convocados los nuevos tribunales arbitrales, en decisiones posteriores anula los laudos proferidos por esos tribunales porque conforme a las interpretaciones prejudiciales iniciales del Tribunal de Justicia de la Comunidad Andina rendidas en esos asuntos, la competencia para conocer de cualquier conflicto durante la ejecución de la interconexión, dentro de éstos los contractuales, corresponde a la Autoridad de Telecomunicaciones del país, en nuestro caso, a la Comisión de Regulación de Comunicaciones.

9. Las interpretaciones prejudiciales iniciales del Tribunal de Justicia de la Comunidad Andina fueron "moduladas" y rectificadas, reconociéndose la eficacia del pacto arbitral en el Derecho Comunitario para dirimir las controversias contractuales sobre asuntos de libre disposición que no involucren materias de orden público.

10. La Resolución 1922 de 2017 de la Secretaria General de la Comunidad Andina en armonía con la Decisión 469 de 1999, art. 32, remite a la competencia de las autoridades nacionales conforme a sus leyes internas.

11. El entendimiento inicial de las normas comunitarias, es hoy diferente: la competencia de la Autoridad de Telecomunicaciones se limita a los asuntos de orden público comprendidos en la regulación, y en los conflictos de libre disposición es eficaz el pacto arbitral.

12. El Concepto rendido al Gobierno Nacional el 24 de octubre de 2016 por la Sala de Consulta y Servicio del Consejo de Estado, es un significativo avance para despejar la problemática.

95 La Corte Constitucional en Sentencia SU-263-15, revocó la sentencia proferida por la Sección Quinta de la Sala de lo Contencioso Administrativo del Consejo de Estado, dictada el 23 de octubre de 2013, que negó la protección de los derechos invocados dentro de la acción de tutela presentada por Comcel S.A. en contra de la Sección Tercera de esa misma corporación. En su lugar, CONFIRMAR el fallo proferido en primera instancia por la Sección Cuarta de la Sala de lo Contencioso Administrativo del Consejo de Estado, que declaró la improcedencia del amparo constitucional".

96 La Corte Constitucional en Sentencia de Tutela T-783-13, concluyó que la actuación del juez 30 Civil del Circuito Municipal confirmada por el Juez 30 Civil del Circuito, y las sentencias pronunciadas por el Tribunal de Cundinamarca y el Consejo de Estado, se ajustan a derecho, en cuanto concierne a la no reconstitución de los tribunales arbitrales cuyos laudos fueron anulados, y a las nuevas convocatorias de tribunales. 


\section{BIBLIOGRAFÍA}

\section{DOCTRINA}

AlCala Zamora y Castillo, NICETO. Proceso, autocomposición y autodefensa, (Contribución al estudio de los fines del proceso) México: Universidad Nacional Autónoma de México- Instituto de Investigaciones Jurídicas, 2000.

AMARIS HERnÁNDEZ, CARMiÑA. "Reglas aplicables a las actuaciones administrativas de solución de controversias en materia de interconexión", en EDGAR GONZÁLEZ LÓPEZ (dir.). Comentarios a la ley de Tecnologías de la Información y las Comunicaciones -TIC. Bogotá: Universidad Externado de Colombia, 2010.

Carnelutti, Francesco. Como nace el Derecho. Sentis Melendo, Santiago y Ayerra Redín, Marino (trad.), 4. ${ }^{a}$ reimpr. de la 3. ${ }^{a}$ ed. Bogotá: Editorial Temis S.A., 2004.

Carnelutti, Francesco. Instituciones del Proceso Civil, vol. I. Sentis Melendo, Santiago (trad.). Buenos Aires: Ediciones Jurídicas Europa-América, 1973.

DieZ-PICAZO, LuIS y PONCE DE LEÓn, Experiencias jurídicas y teoría del Derecho, Barcelona: Editorial Ariel S.A, 1993.

GONZÁLEZ LÓPEZ, EDGAR La función de regulación administrativa de resolución de conflictos. ¿Unas características distintas? Apuntes para su estudio" Perspectivas de una reforma. estudios de derecho administrativo a partir de la obra de Eberhard Schmidt - Assmann, en Colombia ed: Universidad Externado de Colombia ,v. , pp.795-835, 2017

ONZÁLEZ LÓPEZ, EDGAR. "Comentarios sobre la función de resolución de controversias en el sector de las comunicaciones en Colombia" el ecosistema digital y las autoridades de regulación de los sectores audiovisual y TIC. En: ed: Universidad Externado de Colombia, v., pp. 795-835, 2017.

GONZÁlEZ LÓPEZ, EDGAR. La función de solución de conflictos atribuida a las autoridades administrativas especializadas en el sector de las Telecomunicaciones. Los retos del Estado y la administración en el siglo XXI libro homenaje al profesor Tomás de la Quadra-Salcedo Fernández del Castillo, en España. ed: Tirant Lo Blanch, vol. 2m, t 2, pp. 1471-1560, 2017.

Mantilla Espinosa, FABricio. "Los límites al consentimiento en el pacto arbitral". En: SiLVA Romero, EduARdo (dir.). MANTILla EsPinOsa, FABricio (coord.). El Contrato de Arbitraje. $1^{a}$ edición. Bogotá: Legis Editores S.A. Colegio Mayor de Nuestra Señora del Rosario-Facultad de Jurisprudencia, 2005, p. 237 a 254.

MARTinez ArCOS, L.V.. Sobre la inobservancia de la obligación de solicitar en el trámite arbitral la interpretación prejudicial de normas comunitarias al Tribunal 
de Justicia de la Comunidad Andina. Revista de Derecho Privado, Diciembre, 2014, 52. Universidad de los Andes, Colombia.

Pimiento ECHEVERri, Julian Andrés. La regulación. Análisis a partir de las funciones jurisdiccionales de la Comisión de Regulación de Comunicaciones. Revista digital de Derecho Administrativo, n. ${ }^{\circ}$ 9, primer semestre/2013, pp. 15-40. Bogotá: Universidad Externado de Colombia.

VILLEGAS, LORENZO. "La ley de tic y la regulación de las telecomunicaciones: la Comisión de Regulación de Comunicaciones", en ÉDGAR GONZÁLEZ LÓPEZ (dir.). Comentarios a la ley de Tecnologías de la Información y las Comunicaciones -TIC. Bogotá: Universidad Externado de Colombia, 2010.

JURISPRUDENCIA

Corte Constitucional, Sentencia C-517 de 1992.

Corte Constitucional, Sentencia C-276 de 1993.

Corte Constitucional, Sentencia C-225 de 1995.

Corte Constitucional, Sentencia C-228 de 1995.

Corte Constitucional, Sentencia C-031 de 1995.

Corte Constitucional, Sentencia C-069 de 1995.

Corte Constitucional, Sentencia C-397 de 1995.

Corte Constitucional, Sentencia C-137 de 1996.

Corte Constitucional, Sentencia C-263 de 1996

Corte Constitucional, Sentencia C-483 de 1996.

Corte Constitucional, Sentencia C-075 de 1997.

Corte Constitucional, Sentencia C-066 de 1997.

Corte Constitucional, Sentencia C-231 de 1997.

Corte Constitucional, Sentencia C-284 de 1997.

Corte Constitucional, Sentencia C-193 de 1998.

Corte Constitucional, Sentencia C-155 de 1998. 
Corte Constitucional, Sentencia C-256 de 1998.

Corte Constitucional, Sentencia C-272 de 1998

Corte Constitucional, Sentencia C-444 de 1998.

Corte Constitucional, Sentencia C-227 de 1999.

Corte Constitucional, Sentencia T-295 de 1999.

Corte Constitucional, Sentencia C-957 de 1999.

Corte Constitucional, Sentencia T-827 de 1999

Corte Constitucional, Sentencia C-636 de 2000.

Corte Constitucional, Sentencia C-638 de 2000.

Corte Constitucional, Sentencia C-646 de 2000.

Corte Constitucional, Sentencia C-830 de 2010.

Corte Constitucional, Sentencia C-1143 de 2000.

Corte Constitucional, Sentencia C-1162 de 2000.

Corte Constitucional, Sentencia SU-1193 de 2000.

Corte Constitucional, Sentencia C-1369 de 2000.

Corte Constitucional, Sentencia C-1490 de 2000.

Corte Constitucional, Sentencia C-1641 de 2000.

Corte Constitucional, Sentencia T-851 de 2001.

Corte Constitucional, Sentencia C-170 de 2001.

Corte Constitucional, Sentencia C-557 de 2001.

Corte Constitucional, Sentencia C-558 de 2001

Corte Constitucional, Sentencia C-649 de 2001.

Corte Constitucional, Sentencia C-1162 de 2001.

Corte Constitucional, Sentencias C-265 de 2002. 
Corte Constitucional, Sentencia C-290 de 2002.

Corte Constitucional, Sentencia C-389 de 2002.

Corte Constitucional, Sentencia C-426 de 2002.

Corte Constitucional, Sentencia C-616 de 2002.

Corte Constitucional, Sentencia C-791 de 2002.

Corte Constitucional, Sentencia C-35 de 2003.

Corte Constitucional, Sentencia C-150 de 2003.

Corte Constitucional, Sentencia C-503 de 2003.

Corte Constitucional, Sentencia C-741 de 2003.

Corte Constitucional, Sentencia C-1114 de 2003.

Corte Constitucional, Auto No. 054 de 2004.

Corte Constitucional, Sentencia T-088 de 2004.

Corte Constitucional, Sentencia C-988 de 2004.

Corte Constitucional, Sentencia C-644 de 2004.

Corte Constitucional, Sentencia C-1120 de 2005.

Corte Constitucional, Sentencia C-955 de 2007.

Corte Constitucional, Sentencia T-058 de 2009.

Corte Constitucional, Sentencia C-186 de 2011.

Corte Constitucional, Sentencia C-156 de 2013.

Corte Constitucional, Sentencia T-783 de 2013.

Corte Constitucional, Sentencia C-269 de 2014.

Corte Constitucional, Sentencia C-256 de 2014.

Corte Constitucional, Sentencia SU-263 de 2015.

Corte Constitucional, Sentencia T-783 de 2013. 
Consejo de estado, Sala de lo Contencioso Administrativo, Sección Tercera, Sentencia de septiembre 25 de 1997, Exp. 11057.

Consejo de estado, Sala de lo Contencioso Administrativo, Sección Sección Cuarta, Sentencia 9783 de mayo 5 de 2000.

Consejo de estado, Sala Plena, Sentencia de 4 de marzo de 2003, Ref.: Exp. IJ-030.

Consejo de estado, Sala de lo Contencioso Administrativo, Sección 5a, sentencia del 31 de julio de 2003, Radicación 0144-01(AP).

Consejo de estado, Sala de lo Contencioso Administrativo Sección Tercera, Sentencia de 11 de marzo de 2004, expediente número 11001-03-26-000-20030022-01(25021).

Consejo de estado, Sala de lo Contencioso Administrativo, Sección Tercera, sentencia de 21 de mayo de 2008, Radicación Número 10001-03-26-000-200700008-00 (33.643).

Consejo de estado, Sala de lo Contencioso Administrativo, Sección Tercera, Sentencia del 28 de febrero de 2013. Radicación número: 11001-03-15-000-201201785-00(AC).

Consejo de ESTAdo, Sala de lo Contencioso Administrativo, Sección Tercera, Sentencia del 5 de julio de 2013. Radicación número: 11001-0315-000-2012-01785-01.

Consejo de estado, Sala de lo Contencioso Administrativo, Sección Tercera, sentencia del 27 de marzo de 2014, Exp. 26939.

Consejo de estado, Sala de lo Contencioso Administrativo, Sección Tercera sentencia de 27 de marzo de 2012, Radicación Número 11001-03-26-000-200700009-00 (33.644).

Consejo de ESTAdo, Sala de lo Contencioso Administrativo, Sección Tercera, sentencia de 27 de marzo de 2012, Radicación Número y 11001-03-26-000-200700010-01 (33.645).

Consejo de estado, Sala de lo Contencioso Administrativo, Sección Tercera, Sala Plena. Sentencia de 9 de agosto de 2012, Radicación 11001032600020120001800 (43.195).

Consejo de estado, Sala de lo Contencioso Administrativo, Sección Tercera, Sala Plena. Sentencia de 9 de agosto de 2012, Radicación 110010326000201200020 004(43281). 
Consejo de estado, Sala de lo Contencioso Administrativo, Sección Tercera, Sala Plena. Sentencia de 9 de agosto de 2012, Radicación 11001032600020120001300 (43045).

Consejo de estado, Sala de lo Contencioso Administrativo, Sección Tercera, Subsección A, sentencia de noviembre 21 de 2012. Radicación: 110010326000201000056 00 (39.373).

Consejo de estado, Sala de lo Contencioso Administrativo, Sección Tercera, sentencia del 27 de marzo de 2014, Exp. 26939.

Consejo de estado, Sala de lo Contencioso Administrativo, Sección Tercera, Subsección A, Sentencia del 23 de septiembre de 2015, Expediente 11001032600020150001800 (53054).

Consejo de estado, Sala de lo Contencioso Administrativo, Sección Tercera, Sentencia de 2 de diciembre de 2015, Expediente 11001032600020150003000(53182).

Consejo de estado, Sala de lo Contencioso Administrativo, Sección Tercera, Subsección C, Sentencia de 3 de agosto de 2016, Radicación Número11001-03-26-000-2015-00089-00 (54.315).

Consejo de estado, Sala de lo Contencioso Administrativo, Sección Tercera, Subsección C, Sentencia de 10 de noviembre de 2016, Radicación Número 11001 03-26-000-2016-00063-00 (56845).

Consejo de estado, Sala de lo Contencioso Administrativo, Sección Tercera, Subsección C, Sentencia de 24 de noviembre de 2016, Radicación Número 1100103-26-000-2015-00089-00 (54.315).

Consejo de estado, Sala de lo Contencioso Administrativo, Sección Tercera, Subsección B, Sentencia de 7 de diciembre de 2017, Radicación Número 11001032600020140017200 (52.741).

Consejo de estado, Sala de Consulta y Servicio Civil, Concepto 2293 de octubre 24 de 2016, Rad. 2293, Número único 11001-03-06-000-2016-00074-00, Magistrados Germán Alberto Bula Escobar, presidente de la Sala_Oscar Darío Amaya Navas_Luis Fernando Álvarez Jaramillo (conjuez).

Corte Suprema de Justicia, Sala Plena, Sentencia 2066 de junio 20 de 1990.

Corte Suprema de Justicia Sala Plena, Sentencia del 27 de febrero de 1975, Gaceta Judicial, T. 152-153, No 2393-2394, 1975.

Corte Suprema de Justicia Sala Civil, Sentencia de tutela del 18 de marzo de 2009, Exp. 11001-02-03-000-2009-00393-00. 


\section{OTROS DOCUMENTOS CONSULTADOS}

COMISION DE REGULACION DE TELECOMUNICACIONES Y COMISION DE REGULACIÓN DE COMUNICACIONES. Resoluciones 1345 de 2005; Resolución 1388 de 2005, 1479 de 2006, CRT 1715 de 2007, 1757 de 2007, CRC 4401 de 2014.

Comunidad Andina de Naciones, Tribunal de Justicia de la Comunidad Andina. Proceso 02-IP-1991.

Comunidad Andina De Naciones, Tribunal de Justicia de la Comunidad Andina. Proceso 06-IP-1999.

Comunidad ANDina DE NACIONES, (Agosto 3 de 2001). Nota informativa sobre el planteamiento de la solicitud de interpretación prejudicial por los órganos judiciales nacionales. Gaceta Oficial del Acuerdo de Cartagena (694).

Comunidad Andina DE NACIONES, Decisión 462 de 1999 (mayo 25), Cartagena de Indias, Colombia Gaceta 01/06/99.

Comunidad Andina de Naciones, Secretaría General de la Comunidad Andina. Resolución n. ${ }^{\circ}$ 1922. Gaceta Oficial del Acuerdo de Cartagena. Año XXXIV - n. ${ }^{\circ}$ 2989 (2017).

Comunidad Andina de Naciones, Secretaría General de la Comunidad Andina. Resolución 432 de 2000 (octubre 2), Lima Perú.

Comunidad Andina de Naciones, Secretaría General de la Comunidad AnDINA. DICTAMEN 02- 2010.

Comunidad Andina De Naciones, Tribunal de Justicia de la Comunidad Andina. Proceso 07-AI-1999.

Comunidad Andina de Naciones, Tribunal de Justicia de la Comunidad Andina. Proceso 30-IP-1999.

Comunidad Andina de Naciones, Tribunal de Justicia de la Comunidad Andina. Proceso 14-IP-2007.

Comunidad Andina de Naciones, Tribunal de Justicia de la Comunidad Andina. Proceso 130-IP-2007.

Comunidad Andina de Naciones, Tribunal de Justicia de la Comunidad Andina Proceso 03-AI-2010, Acción de incumplimiento de la Empresa de Telecomunicaciones de Bogotá S.A. ESP, (ETB S.A. E.S.P.) contra la República de Colombia, Sección Tercera del Consejo de Estado. Sentencia de 26 de agosto de 2011 y providencias de 15 de 2011 y 18 de julio de 2012. 
Comunidad Andina De Naciones, Tribunal de Justicia de la Comunidad Andina. Interpretación Prejudicial 181-IP-2013.

Comunidad Andina de Naciones, Tribunal de Justicia de la Comunidad Andina. Interpretación Prejudicial 261-IP-2013.

Comunidad Andina de Naciones, Tribunal de Justicia de la Comunidad Andina. Interpretación Prejudicial 79-IP-2014.

Comunidad Andina de Naciones., Tribunal de Justicia de la Comunidad Andina. Proceso 57-IP-2012.

Comunidad Andina de Naciones, Tribunal de Justicia de la Comunidad Andina. Proceso 16-IP-2014.

Comunidad Andina de Naciones, Tribunal de Justicia de la Comunidad Andina. Interpretación Prejudicial 366-IP-2015.

Comunidad Andina de Naciones, Tribunal de Justicia de la Comunidad Andina. Interpretación Prejudicial 385-IP-2015.

Comunidad Andina de Naciones, Tribunal de Justicia de la Comunidad Andina. Interpretación Prejudicial 560-IP-2016. 